\title{
Lactiplantibacillus plantarum 299v (LP299V®): three decades of research
}

\author{
E. Arvidsson Nordström ${ }^{1 *}$, C. Teixeira ${ }^{1}$, C. Montelius ${ }^{1}$, B. Jeppsson ${ }^{2}$ and N. Larsson ${ }^{1}$ \\ ${ }^{1}$ Probi AB, Ideongatan 1A, 22370 Lund, Sweden; ${ }^{2}$ Department of Surgery, Lund University, Universitetssjukhuset, 22184 \\ Lund, Sweden; elisabet.nordstrom@probi.com
}

Received: 25 September 2020 / Accepted: 10 June 2021

(c) 2021 Wageningen Academic Publishers

OPEN ACCESS (1) (1)(2) REVIEW ARTICLE

\begin{abstract}
This review aims to provide a comprehensive overview of the in vitro, animal, and clinical studies with the bacterial strain Lactiplantibacillus plantarum 299v (L. plantarum 299v; formerly named Lactobacillus plantarum 299v) published up until June 30, 2020. L. plantarum 299v is the most documented L. plantarum strain in the world, described in over 170 scientific publications out of which more than 60 are human clinical studies. The genome sequence of L. plantarum 299v has been determined and is available in the public domain (GenBank Accession number: NZ_LEAV01000004). The probiotic strain L. plantarum 299v was isolated from healthy human intestinal mucosa three decades ago by scientists at Lund University, Sweden. Thirty years later, a wealth of data coming from in vitro, animal, and clinical studies exist, showing benefits primarily for gastrointestinal health, such as reduced flatulence and abdominal pain in patients with irritable bowel syndrome (IBS). Moreover, several clinical studies have shown positive effects of L. plantarum $299 \mathrm{v}$ on iron absorption and more recently also on iron status. L. plantarum $299 \mathrm{v}$ is safe for human consumption and does not confer antibiotic resistance. It survives the harsh conditions of the human gastrointestinal tract, adheres to mannose residues on the intestinal epithelial cells and has in some cases been re-isolated more than ten days after administration ceased. Besides studying health benefits, research groups around the globe have investigated L. plantarum $299 \mathrm{v}$ in a range of applications and processes. L. plantarum $299 \mathrm{v}$ is used in many different food applications as well as in various dietary supplements. In a freezedried format, L. plantarum $299 \mathrm{v}$ is robust and stable at room temperature, enabling long shelf-lives of consumer healthcare products such as capsules, tablets, or powder sachets. The strain is patent protected for a wide range of indications and applications worldwide as well as trademarked as LP299V ${ }^{\odot}$.
\end{abstract}

Keywords: irritable bowel syndrome, probiotic, digestive health, iron absorption

\section{Introduction}

The history of Lactiplantibacillus plantarum (L. plantarum) $299 \mathrm{v}$ began in the 1980s, when a group of scientists at Lund University in southern Sweden was struggling to find ways to increase survival in intensive care unit (ICU) patients with multiple organ failure. These patients had signs of sepsis with failing respiratory, renal, and hepatic function and high mortality rates despite intensive care and antibiotic therapy. Critical illness is often associated with significant gut overgrowth of typical ICU pathogens, such as Clostridioides difficile, Enterobacteriaceae and enterococci, and bacterial translocation may be a factor of importance in the pathogenesis of ICU-acquired infections. The indigenous intestinal microbiota therefore plays an important role in protecting the gut from colonisation with exogenous pathogens as well as overgrowth of endogenous commensal bacteria. Treatment with narrow or broad-spectrum antibiotics could partially be the cause of gut microbial imbalance since these disrupt the normal microbiota and promote colonisation of pathogens (Marshall et al., 1993; Palleja et al., 2018).

\section{Isolation, intestinal persistence, and safety}

L. plantarum $299 \mathrm{v}$ was isolated from healthy intestinal mucosa (Ahrné et al., 1998; Molin et al., 1993), and reisolated after consumption (Johansson et al., 1993). L. plantarum strains are common in traditional lactic acidfermented foods of plant origin, such as brined olives, 
capers, sauerkraut, sour-dough and wine (Molin, 2001), and different L. plantarum strains, including L. plantarum $299 \mathrm{v}$, were found to frequently occur in the normal intestinal microbiota of healthy adults (Ahrné et al., 1998). L. plantarum 299v has been characterised using different methods: restriction fragment length polymorphism (RFLP) (Johansson et al., 1995a), restriction endonuclease analysis (REA) (Johansson et al., 1995b), randomly amplified polymorphic DNA (RAPD) (Johansson et al., 1995c; Nigatu et al., 2001) and microarray analysis (Marco et al., 2010; Molenaar et al., 2005). Additionally, global gene expression profiles of L. plantarum 299v have been conducted on human intestinal tissue biopsies (Marco et al., 2010).

The rapid development of new sequencing technologies over the last few years has triggered the review of the taxonomy of microorganisms in more detail. As a result, a 'reclassification' of certain Lactobacillus species into new genera has been made (Zheng et al., 2020). Lactobacillus plantarum was renamed Lactiplantibacillus plantarum.

\section{Ability to survive and persist in the gastrointestinal tract}

The strain L. plantarum 299v has been shown in multiple in vitro and clinical studies to survive the harsh conditions in the human gastrointestinal (GI) tract (Goossens et al., 2003, 2005, 2006a,b; Hamon et al., 2011; Jacobsen et al., 1999; Jensen et al., 2012; Johansson et al., 1993, 1998; Onning et al., 2003). When incubated at $\mathrm{pH} 2.5$, L. plantarum $299 \mathrm{v}$ was found to survive for four hours (Jacobsen et al., 1999). During a simulated transit through the upper GI tract, the viability of $L$. plantarum $299 \mathrm{v}$ was reduced after incubation with simulated gastric juice, but not with simulated small intestinal juice (Jensen et al., 2012). Furthermore, $L$. plantarum $299 \mathrm{v}$ was one of the L. plantarum strains best suited to grow in culture broth supplemented with bile salts (Hamon et al., 2011).

In a clinical setting, L. plantarum $299 \mathrm{v}$ in combination with either placebo or the proton pump inhibitor pantoprazole was given to 32 subjects, with the hypothesis that decreased stomach acid production by pantoprazole would increase survival of lactobacilli. L. plantarum $299 \mathrm{v}$ was found in all faecal samples, from the pantoprazole as well as the placebo group, during the week of probiotic administration. Hence, L. plantarum 299v survives the passage through the gastrointestinal tract irrespective of the gastric acidity (Goossens et al., 2005).

Along with its ability to survive the harsh GI conditions, several clinical studies have demonstrated that L. plantarum $299 \mathrm{v}$ has excellent persistence capacity and can be reisolated from mouth to rectum. L. plantarum $299 \mathrm{v}$ was one of the dominating lactobacilli strains in intestinal mucosa samples taken from the upper jejunum 11 days after the end of administration of a mix of 19 different strains (Johansson et al., 1993). Moreover, the strain was re-isolated from faeces eight days after the last administration in a fruit drink (Johansson et al., 1998) and four weeks after the last administration in an oat drink (Goossens et al., 2005). Mucosal biopsies taken from both rectum and colon show that there is no difference in L. plantarum $299 \mathrm{v}$ prevalence or bacterial concentration between these two GI regions (Goossens et al., 2006a).

\section{Safety}

L. plantarum $299 \mathrm{v}$ has been thoroughly tested in humans and proven to be safe for consumption by healthy adults and children as well as individuals with various health conditions. The species L. plantarum is recognised as safe and included on the Qualified Presumption of Safety (QPS) list in the European Union. To be on the QPS list, a microorganism must have a well-defined taxonomic identity and its safety must be well established. Moreover, the microorganism (strain) must not have any pathogenic properties (virulence factor or toxin production), it should have an acceptable antibiotic resistance profile (as defined by the European Food Safety Authority (EFSA, 2018)) and a clear intended use (EFSA, 2020). The Food and Drug Administration (FDA) in the United States has reviewed the evidence provided in the Generally Recognised as Safe (GRAS) determination notice for L. plantarum $299 \mathrm{v}$ and concluded they had no further questions about, nor any objection to, its intended use. For a substance to be considered GRAS it must be generally recognised, among qualified experts, as safe under the conditions of its intended use.

L. plantarum 299v has been safely administered to vulnerable populations, such as patients undergoing elective major abdominal surgery (McNaught et al., 2002), critically ill patients (Klarin et al., 2005, 2008; McNaught et al., 2005; Oudhuis et al., 2011), children as young as 6-12 months (Berggren et al., 2003; Kingamkono et al., 1999; Olek et al., 2017), children congenitally exposed to HIV-1 who were diagnosed with failure to thrive (Cunningham-Rundles et al., 2000, 2011), children with small bowel bacterial overgrowth (Vanderhoof et al., 1998) and children and adolescents undergoing hematopoietic cell transplantation (Ladas et al., 2016). The studies suggest that administration of $L$. plantarum $299 \mathrm{v}$ may even alleviate side effects coupled to invasive treatment (Ladas et al., 2016) and positively influence growth and immune development in HIV1 positive children (Cunningham-Rundles et al., 2000; Cunningham-Rundles et al., 2011). Moreover, L. plantarum $299 \mathrm{v}$ given to rats undergoing cancer chemotherapy improved food intake and body weight, as well as reduced the number of facultative anaerobes in the intestine, as compared to the control animals (Von Bultzingslowen et al., 2003). 
To further evaluate safety and risk of septic bacteraemia, an endocarditis animal model was used for a comparison between L. plantarum 299v and a Staphylococcus lugdunensis control group. $96 \mathrm{~h}$ after injection into the tail vein of rats, no lactobacilli were found in the heart, blood, or catheter, while S. lugdunensis was isolated from both blood and heart (Adawi et al., 2002).

The bacterial content is high in the intestine and so is the likelihood of horizontal gene transfer between bacteria, such as those encoding antibiotic resistance. Re-isolated L. plantarum $299 \mathrm{v}$ from critically ill patients treated with broad-spectrum antibiotics were tested against 22 different antibiotics. There was no obvious decrease in susceptibility to 21 of the tested antibiotics and only a tendency towards decreased susceptibility to ampicillin. The authors therefore concluded that L. plantarum $299 \mathrm{v}$ is less likely to acquire antibiotic resistance when administered to critically ill patients treated with broad-spectrum antibiotics (Klarin et al., 2019).

\section{Mechanisms}

L. plantarum 299v has been shown to benefit multiple areas of the body, especially the GI tract. Although not yet fully understood, maintenance and improvement of gut mucosal barrier function seems to be the core principle behind the GI health benefits of L. plantarum 299v. A healthy and more resilient mucosa can better tackle foreign elements (e.g. pathogens and their secreted substances), and in this way reduce local and systemic inflammation (Williams, 2003). Mucosal defence mechanisms include physical barriers, such as mucus secretion and selectively permeable epithelial cell layers with tight cell-cell connections, whereas nonphysical barrier mechanisms include secretion of signalling molecules and respective receptors (Chaplin, 2010).

\section{Adherence to epithelial cells}

The ability of $L$. plantarum $299 \mathrm{v}$ to survive the passage through the GI tract and to adhere to epithelial cells is important for the health benefits of this strain and could explain the reduction of GI symptoms in irritable bowel syndrome (IBS) and the increased iron absorption, discussed in detail in later sections.

L. plantarum 299v adheres to the epithelial cells along the entire digestive tract in healthy adults (Johansson et al., 1993, 1998; Mangell et al., 2012; Nobaek et al., 2000; Stjernquist-Desatnik et al., 2000) and in critically ill patients (Klarin et al., 2005). The mannose-binding mechanism is the best-known function enabling L. plantarum 299v to adhere to the intestinal epithelium (Adlerberth et al., 1996). The binding mechanism is comprised of an adhesin present in the cell wall of the bacteria that attaches to mannose residues expressed on the surface of eukaryotic cells, e.g. on intestinal epithelial cells. The gene encoding the mannose-specific adhesin (Msa; gene name $m s a$ ) has been identified (Pretzer et al., 2005) as the only responsible gene for this type of adhesion (Gross et al., 2010), since its absence directly impairs the adhesion of $L$. plantarum $299 \mathrm{v}$ to yeast (rich in mannose residues), Caco-2 cells (Holst et al., 2019), and HT29 cells (Mack et al., 2003). Mannosebinding capacity was shown to vary between $L$. plantarum strains (Tallon et al., 2007) and L. plantarum 299v seems to have higher capacity compared to the strain WCFS1 (Gross et al., 2010). This variation of binding capacity between strains seems to be regulated by a promoter region upstream of the msa gene (Holst et al., 2019), rather than the sole presence of $m s a$ itself (Pretzer et al., 2005) or the domain composition of Msa protein (Gross et al., 2010).

Although Msa protein is essential for binding to the epithelium, adhesion to the mucus layer is required to allow enough residence time for commensal bacteria to interact with the epithelial cells and thus exert their beneficial effects. L. plantarum $299 \mathrm{v}$ seems to adhere to mucus mostly due to electrostatic and hydrophobic interactions with the mucin (Buntin et al., 2017). Surface-bound enzymes, such as glyceraldehyde 3-phosphate dehydrogenase (GAPDH) possibly mediate these interactions by being able to bind to mucin, as shown in Caco-2 cells (Glenting et al., 2013). Other cell surface molecules mediating the attachment of epithelial cells such as glycolytic enzymes, proteins involved in stress response and ribosomal proteins, have also been identified (Beck et al., 2009; Glenting et al., 2013; Gross et al., 2008a; Izquierdo et al., 2009; Saad et al., 2009).

\section{Pathogen inhibition}

Competitive exclusion due to occupying binding sites, production of short-chain fatty acids (SCFAs) that lower the $\mathrm{pH}$ in the intestinal milieu, induced production of mucin and production of bacteriocins are some of the proposed mechanisms for pathogen inhibition by probiotics. Mucin production seems to be the strongest pathogen inhibition mechanism induced by L. plantarum 299v, followed by carboxylic acid production, whereas the results from studies on competition for binding sites are somewhat inconclusive. The mechanism can also be indirect, since L. plantarum $299 \mathrm{v}$ has been shown to affect the overall microbiota composition and increase diversity (Karlsson et al., 2010), which is more thoroughly discussed in Section 4 - Potential mode of action.

Mucin production is a first line defence against pathogens in the intestinal lumen. The direct adherence of $L$. plantarum $299 \mathrm{v}$ to the epithelial cells seems to facilitate cellular communication with the epithelium to promote mucin production (Mack et al., 1999, 2003) and could be one of the keys to promote intestinal barrier integrity. In the intestinal cell line HT29, L. plantarum 299v was shown to 
rapidly upregulate mRNA expression of the mucin genes $M U C 2$ and $M U C 3$, and consequently mucin production (Mack et al., 1999). In contrast, when L. plantarum 299v lacked mannose-binding adherence ability (Mack et al., 2003), or were heat-killed (Dykstra et al., 2011), mRNA expression of MUC3 was not upregulated (Mack et al., 2003). L. plantarum $299 \mathrm{v}$ in combination with caprine milk carbohydrate fraction increased mRNA levels of $M U C 4$, $M U C 2$ and MUC5AC in a co-culture of Caco-2 and HT29 cells. However, protein abundance was only confirmed for MUC4 mucin, one of the major components of the glycocalyx (Barnett et al., 2018).

Bacterial fermentation products, such as the SCFAs acetic acid, butyric acid, and propionic acid contribute to a healthy intestinal barrier. SCFAs are partly absorbed by the intestinal cells to serve as energy to maintain cellular biological functions, and are partly accumulated in the intestinal lumen, contributing to pathogen inhibition by decreasing the $\mathrm{pH}$. L. plantarum $299 \mathrm{v}$ is a lactic acid producer (Goossens et al., 2006a) rather than a producer of SCFAs, however, lactic acid is a precursor of some SCFAs (Bourriaud et al., 2005). Enhanced lactic acid production after intake of $L$. plantarum $299 \mathrm{v}$ may explain the significant increase in acetic acid and propionic acid production in healthy subjects (Johansson et al., 1998), the significant increase in plasma propionic acid in men with stable coronary artery disease (Malik et al., 2018) and the maintained, rather than decreased, faecal butyric acid levels in patients under antibiotic treatment (Wullt et al., 2007). The latter result suggests that administration of $L$. plantarum 299v reduces the negative effects of antibiotic treatment on colonic fermentation.

Several pathogenic bacteria are known to have the same type of adherence to mannose as L. plantarum $299 \mathrm{v}$ (Stones and Krachler, 2015). Competition for the same binding sites on the intestinal cells, known as competitive exclusion, is one of the hypotheses for the defence mechanism of this strain (Gross et al., 2010; Reid and Burton, 2002). L. plantarum 299v was found to inhibit the attachment of one strain of Escherichia coli to Caco-2 cells in vitro using Ussing chambers, but only when the probiotic bacteria were added before the E. coli infection (Michail and Abernathy, 2002). However, L. plantarum 299v did not inhibit phytohemagglutinin (PHA)-induced overgrowth of $E$. coli in suckling rats, although they were administered prior to PHA (Gross et al., 2008b). In an in vitro study using the non-intestinal cell line HEp-2, expressing only minimal levels of $M U C 2$ and no MUC3 mRNA, E. coli binding was not inhibited, nor dislodged, by L. plantarum $299 \mathrm{v}$, possibly due to the low levels of mucin produced by these cells (Mack et al., 1999). As discussed above, the promotion of MUC3 mucin by L. plantarum $299 \mathrm{v}$ appears to be of particular importance in pathogen inhibition and may be the main mechanism for hindering E. coli adherence to the epithelial cells, rather than competitive exclusion. Clinical studies are necessary to evaluate the ability of L. plantarum $299 \mathrm{v}$ to inhibit attachment of $E$. coli in human intestine.

The interaction between L. plantarum $299 \mathrm{v}$ and other pathogenic bacteria that do not share the same binding mechanism has also been studied. In an in vitro study, L. plantarum $299 \mathrm{v}$ was shown to have intermediate antagonistic activity against Helicobacter pylori and Salmonella enterica ssp. enterica (Hutt et al., 2006). However, another in vitro study did not show inhibition of Salmonella enteritidis 857 growth (Malago et al., 2010), which was confirmed in a clinical setting where $L$. plantarum $299 \mathrm{v}$ was not able to accelerate clearance of Salmonella or reduce its associated symptoms (Lonnermark et al., 2015). Further clinical studies are warranted to obtain conclusive results regarding the actions of L. plantarum $299 \mathrm{v}$ in Salmonella infections, and to investigate whether its efficacy could depend on the strain of the pathogen.

The effect of L. plantarum 299v in C. difficile infections has also been investigated in both in vitro and clinical settings. Despite the lack of antagonistic activity against C. difficile in vitro (Hutt et al., 2006), L. plantarum 299v was shown to reduce the incidence of $C$. difficile infections in several clinical studies (Dudzicz et al., 2018; Klarin et al., 2008; Kujawa-Szewieczek et al., 2015). One clinical study included 3,533 hospitalised patients treated with immunosuppressive agents. It was found that the incidence of $C$. difficile infection in the ward was significantly reduced during the one-year period when supplementation of L. plantarum $299 \mathrm{v}$ was implemented, compared to the previous year (Kujawa-Szewieczek et al., 2015). A followup study including in total 5,341 subjects showed that the incidence significantly increased again during the one year period after the supplementation ceased (Dudzicz et al., 2018).

\section{Permeability and bacterial translocation}

The improvement of gut barrier function by L. plantarum $299 \mathrm{v}$ has been studied in different animal models assessing permeability and bacterial translocation. Similar to several other health benefits of L. plantarum 299v, reduction of permeability seems to be related to the mannose-binding property of this strain. Pre-treatment with $L$. plantarum $299 \mathrm{v}$ has been shown to prevent increased intestinal permeability induced by $E$. coli in healthy rat models (Mangell et al., 2002), and to reduce lipopolysaccharideinduced bacterial translocation into mesenteric lymph node and liver of endotoxemic rats (Mangell et al., 2006). This effect was only observed in L. plantarum $299 \mathrm{v}$ with adherence capacity, and not when the mannose-binding was lost (Mangell et al., 2006). Moreover, an ex vivo study 
showed that only L. plantarum $299 \mathrm{v}$ with adherence capacity decreased net fluid absorption over pig jejunal tissue (Gross et al., 2008a). L. plantarum 299v also showed ability to enhance tight junction integrity as measured by the transepithelial electrical resistance in Caco- 2 cells (Anderson et al., 2010) and in a co-culture of Caco-2 and HT29 cells (Barnett et al., 2018). Moreover, transcription levels of the plasma-membrane protein occludin (important for tight junction stability and barrier function) were increased in Caco-2 and HT29 cells during co-incubation of $L$. plantarum $299 \mathrm{v}$ with the carbohydrate fraction from caprine milk (Barnett et al., 2018).

Bacterial translocation was reduced in rat models of acute pancreatitis (Mangiante et al., 1999, 2001a) and acute liver failure with both rectal (Adawi et al., 1997, 1998, 2001; Wang et al., 2001) and oral (Kasravi et al., 1997) administration of L. plantarum 299v. L. plantarum 299v also decreased permeability in rats with dextran sulphate sodium induced colitis (Osman et al., 2004) and with methotrexate induced enterocolitis (Mao et al., 1996a,b). L. plantarum $299 \mathrm{v}$ given to rat dams during the last week of gestation and during lactation colonised the dams as well as the pups and improved gut growth and gut barrier function in the pups (Fak et al., 2008b). When the bacteria were fed directly to rat pups during the first week of life, gut barrier function was improved, with a more pronounced effect in the youngest pups (Fak et al., 2008a). Furthermore, L. plantarum $299 \mathrm{v}$ was shown to be important in the maturation of gut function of suckling piglets (Wang et al., 2019).

Clinical studies investigating intestinal integrity have primarily been done in patients rather than healthy volunteers. Pre-treatment with L. plantarum $299 \mathrm{v}$ reduced intestinal permeability in patients undergoing biliary drainage, measured by the lactulose/mannitol absorption test (Jones et al., 2013). Using the same absorption test in critically ill patients, permeability was however only mildly reduced (Klarin et al., 2008) or not affected (McNaught et al., 2005). The discrepant results may be explained by the degree of disease severity, since the reliability of this test in critically ill patients has been contested (Fink, 2002; Oudemans-Van Straaten et al., 2002). In two other clinical studies, the presence of bacteria in mesenteric lymph nodes isolated during surgery was used to measure bacterial translocation. In patients referred for colonic resection (Mangell et al., 2012) and in patients with elective major abdominal surgery (McNaught et al., 2002) bacterial translocation was not reduced by intake of $L$. plantarum $299 \mathrm{v}$. Despite these results, L. plantarum 299v has been shown to affect overall intestinal barrier functions, such as mucin production and pathogen inhibition. The need for conclusive clinical studies on paracellular permeability per $s e$ has also been addressed by Ahrné and Hagslätt (2011).

\section{Inflammatory response}

In addition to effects on physical and non-physical mucosal defence mechanisms, probiotic strains may also have direct immunoregulatory properties such as enhancing the activity of macrophages and natural killer (NK) cells or modulating the secretions of antibodies or cytokines (La Fata et al., 2018). There is constant interaction between the mucosal immune system and bacteria in the GI tract, and the immune homeostasis (the balance between tolerance and defence) is important (Peterson et al., 2015). Probiotics may upregulate or downregulate pro- or anti-inflammatory responses aiming to maintain this balance (Isolauri et al., 2001). The potential immunomodulatory activity of $L$. plantarum 299v has been evaluated in several clinical studies, as well as in animal and in vitro studies.

Studies using human mononuclear cells show that the immunomodulatory effects of probiotics differ and depend on immune system maturation and age (Peoples et al., 2009; Tatad et al., 2008), healthy versus diseased conditions (Pathmakanthan et al., 2004; Van Hemert et al., 2010), individual variations (Azad et al., 2018; Van Hemert et al., 2010) as well as strain-specific effects.

The importance of the mannose binding capacity of $L$. plantarum 299v for cytokine expression and secretion has been shown in several in vitro studies (Gross et al., 2008a; McCracken et al., 2002). This was, however, not confirmed in an ex vivo study using human colonic mucosa, since $L$. plantarum 299v showed down-regulatory effects on the immune system independent of the $m s a$ gene (Bauerl $e t$ al., 2013). Moreover, in murine dendritic cells, lethally irradiated L. plantarum $299 \mathrm{v}$ was found to still affect cytokine secretion (Christensen et al., 2002).

McCracken and colleagues (McCracken et al., 2002) found that mRNA expression of the chemokine interleukin (IL)-8, was upregulated in HT29 cells incubated with $L$. plantarum $299 \mathrm{v}$, and that the effect was even more pronounced when the bacteria were co-incubated with HT29 cells treated with the pro-inflammatory cytokine tumour necrosis factor alpha (TNF- $\alpha$ ). Interestingly, this did not result in increased secretion of IL-8 protein, suggesting that $L$. plantarum $299 \mathrm{v}$ could exert a protective effect by preventing an excessive IL-8 secretion. Moreover, in monocytic cell lines L. plantarum 299v had little effect on the secretion of IL-8 and TNF- $\alpha$ (Jensen et al., 2015).

In general, the immunoregulatory effects of $L$. plantarum $299 \mathrm{v}$ are anti-inflammatory in animal studies. In the IL10-deficient mouse model for inflammatory bowel disease (IBD), oral administration of $L$. plantarum $299 \mathrm{v}$ caused a decrease in colonic mucosal interferon gamma (IFN- $\gamma$ ), IL-12 and immunoglobulin (Ig)-G2a levels (Schultz et al., 
2002). A slight downregulation of TNF- $\alpha$ and IL-10 was observed in liver perfusate from healthy rats who were fed L. plantarum $299 \mathrm{v}$ for seven days prior to laparotomy and bile duct ligation (Badger et al., 2013). In pigs, $L$. plantarum 299v seemed to prevent the development of intestinal inflammation by inducing repression of nuclear factor kappa-light-chain-enhancer of activated B cells (NF$\mathrm{kB})$-mediated transcription and peroxisome proliferatoractivated receptor gamma (PPAR- $\gamma$ ) signalling (Hulst et al., 2015).

IgA antibodies are thought to be increased as a response to enhanced intestinal immunity. Germ-free rats, supplemented with L. plantarum $299 \mathrm{v}$ together with $E$. coli $\mathrm{O} 6: \mathrm{K} 13: \mathrm{H} 1$ (originally isolated from urine of a patient with cystitis) resulted in significantly higher total serum IgA levels but only marginally higher IgM, compared to the rats given E. coli alone (Herias et al., 1999). Enterocolitis rat models also showed increased ileal and colonic secretory IgA levels and increased numbers of $\mathrm{T}$ helper cells and cytotoxic $\mathrm{T}$ cells compared to control enterocolitis rats (Mao et al., 1996b). In a study with preweaning calves, L. plantarum 299v given in the milk from seven days of age until start of weaning showed improved growth performance and increased immune capacity (increased plasma levels of IgG, IgA, total superoxide dismutase, IFN- $\gamma$ and soluble CD4, and decreased IL-6) (Jiang et al., 2020). However, in lupus-prone mice, L. plantarum 299v had only little effect on lupus progression and survival, in contrast to other Lactobacillus strains studied (Manirarora et al., 2020).

The immunomodulatory effects of L. plantarum 299v have also been investigated in clinical studies. In contrast to the animal studies discussed above, IgA antibodies were not affected in patients receiving L. plantarum $299 \mathrm{v}$ prior to elective abdominal surgery. Moreover, mucosal IgM levels were increased only in patients not receiving $L$. plantarum $299 \mathrm{v}$, which may indicate increased bacterial translocation in these patients (Woodcock et al., 2004). In critically ill patients treated with antibiotics, L. plantarum $299 \mathrm{v}$ significantly decreased serum levels of the proinflammatory cytokine IL-6 (McNaught et al., 2005). A decrease in systemic IL-6 levels was also seen when the bacteria were given to smokers (Naruszewicz et al., 2002), but not in men with atherosclerotic plaque (Karlsson et al., 2010) or in subjects with major depressive disorders (Rudzki et al., 2019).

An increased expression of IL-12 in peripheral blood mononuclear cells from healthy volunteers was observed when the cells were co-cultured with L. plantarum 299v (Rask et al., 2013). However, in an uncontrolled study in men with coronary artery disease (CAD), supplementation with $L$. plantarum $299 \mathrm{v}$ for six weeks resulted in decreased plasma levels of IL-8 and IL-12 (Malik et al., 2018). Since IL-12 contributes to the activation of phagocytes through inducing IFN- $\gamma$ production by $\mathrm{T}$ lymphocytes and NK cells, this contrast between healthy and diseased subjects may suggest that L. plantarum $299 \mathrm{v}$ assists the immune system in maintaining an alert and proactive immune regulation depending on need. This phenomenon can be seen in subjects suffering from IBS, where intake of $L$. plantarum $299 \mathrm{v}$ has been shown to result in dampening and relief of symptoms which are coupled to immune responses (discussed more thoroughly in Section 4). Hence, L. plantarum $299 \mathrm{v}$ seems to activate the immune system to maintain health but can also dampen the immune response in subjects with ongoing low-grade inflammation.

\section{Irritable bowel syndrome}

IBS is the most commonly reported GI disorder affecting 10-20\% of the population worldwide (Canavan et al., 2014). IBS is primarily characterised by recurrent abdominal pain or discomfort, associated with changes in bowel habits. Depending on the predominance of the bowel habit disorder, IBS can be classified as IBS-D with predominant diarrhoea, IBS-C with predominant constipation, or IBS-M with a combination of both diarrhoea and constipation. Although not required for an IBS diagnosis, abdominal bloating, straining during defecation, defecatory urgency, feeling of incomplete evacuation, or presence of mucus in the stool are common in people suffering from IBS (Mearin et al., 2016; Quigley, 2008). The Rome IV Diagnostic Criteria have since 2016 been used to help diagnose functional GI disorders, such as IBS (Drossman and Hasler, 2016; Lacy et al., 2016). The studies that will be discussed in this section were all performed before 2016, and therefore based on Rome II and Rome III criteria, in which abdominal pain and discomfort were considered main symptoms. In Rome III, the frequency of the symptoms required was 3 days per month during 3 consecutive months, but for clinical trials it was recommended to include subjects who had a frequency of at least two days a week.

The factors influencing the onset of IBS are not well known and can differ between individuals, but microbiota imbalance, also known as dysbiosis, may be one key parameter (Lacy et al., 2016). A disturbed microbiota may over-activate the innate immune responses, which in turn could increase intestinal permeability and result in the GI symptoms typical in IBS (Simren et al., 2013). This is discussed in more detail in Section 4 - Potential mode of action.

\section{Bloating and flatulence}

One of the earliest clinical studies with L. plantarum 299v in subjects with IBS aimed to understand the associated microbiota imbalance and changes with supplementation (Nobaek et al., 2000). The study showed that a fruit drink with $L$. plantarum $299 \mathrm{v}$ was able to reduce flatulence and 
number of days with abundant gas production significantly and more rapidly compared to placebo. This result was somewhat expected since in healthy volunteers, this strain had previously been shown to persist in the gut, reduce potentially gas producing bacteria and perceived flatulence, and increase faecal carboxylic acid concentration (Johansson et al., 1998). A more recent and larger placebo-controlled study in IBS subjects given L. plantarum 299v in freezedried form (capsules) showed significant improvements in both severity and frequency of bloating (Ducrotte et al., 2012). Moreover, upon intake of L. plantarum 299v in conjunction with lactulose, reduced breath hydrogen concentration in subjects with IBS was seen (Sen et al., 2002). Hence, the above studies suggest decreased gas production in the colon caused by intake of $L$. plantarum $299 \mathrm{v}$, which may be of importance in people with IBS since they often suffer from flatulence and bloating (King et al., 1998).

\section{Abdominal pain}

The decreased flatulence shown in the studies by Nobaek et al. (2000) and Johansson et al. (1998) prompted further placebo-controlled clinical studies with focus on other IBS-related symptoms, such as abdominal pain. In the first study, subjects with IBS were randomised to receive either placebo or L. plantarum 299v for 4 weeks. The intervention resulted in resolution of abdominal pain, with a significant pain relief in $70 \%$ of the subjects in the active group after only one week of probiotic administration. At the end of the study, $55 \%$ of subjects in the placebo group still reported pain, in contrast to none of the subjects in the probiotic group (Niedzielin et al., 2001). These results were confirmed in a larger placebo-controlled trial with 204 IBS subjects completing the intervention of 4 weeks. A significant reduction in abdominal pain severity and frequency was achieved, compared to placebo (Ducrotte et al., 2012).

\section{Bowel movement}

L. plantarum 299v has been reported to improve stool frequency, both to reduce the bowel movement in those with at least three defecations per day (Ducrotte et al., 2012), and to increase the bowel movement in those with constipation (Niedzielin et al., 2001). Moreover, in an IBS mouse model, L. plantarum $299 \mathrm{v}$ was shown to normalise intestinal transit rates (Waugh et al., 2009). Considering the results in these studies, it is suggested that L. plantarum $299 \mathrm{v}$ can normalise stool frequency independently of the IBS type. Some L. plantarum strains have been shown to catabolise arginine and thereby generate nitric oxide (NO), which may exert a positive effect on the motility of the large and small intestine. Hence, the mode of action may involve generation of NO (Jonsson et al., 1983).

\section{Overall symptoms}

Changes in overall IBS symptoms were apparent in two of the studies described above. In the study by Niedzielin et al. (2001), 95\% of the subjects receiving L. plantarum $299 \mathrm{v}$ showed an improvement of overall IBS symptoms, compared to $15 \%$ in the placebo group. These results were confirmed in the study by Ducrotté et al. (2012), where 78\% of the subjects receiving probiotics rated their improvement of overall IBS symptoms as 'good' or 'excellent', in contrast with a positive rating of only $8 \%$ of the subjects in the placebo group. Moreover, the investigators assessed the improvement of symptoms similarly to the participants (Ducrotte et al., 2012). Both the study participants and the investigators were blinded to the type of product that had been consumed when rating the efficacy of the product.

The IBS severity scoring system (IBS-SSS) was used by Stevenson et al. (2014) to assess the efficacy of L. plantarum $299 \mathrm{v}$, compared to placebo, in an 8-week intervention. The authors are referring to abdominal pain relief although the IBS-SSS is comprised of five different symptom scores, and compare their results with those seen in the studies by Niedzielin et al. (2001) and Ducrotté et al. (2012). The results, not showing a superiority of L. plantarum 299v on total IBS-SSS, are however not comparable with the individual effects on symptom relief seen in the previous studies, since different parameters were evaluated. Moreover, a large placebo effect was seen in the study by Stevenson et al. (2014) and the authors suggested that this might be one of the main explanations for the lack of results. The study included several visits with clinicians, potentially explaining the big improvements in quality of life seen for all participants. The challenges of the large placebo effect often seen in IBS studies are further discussed in Section 4 - Challenges with IBS studies.

\section{Potential mode of action}

The mechanism by which probiotics may be able to alleviate symptoms of IBS is not clear, but the effects on each IBS symptom are believed to be strain specific (Ortiz-Lucas et al., 2013). A low microbial diversity, particularly in the small intestine, has been associated with increased permeability, and consequently symptoms of GI disorders (Saffouri et $a l ., 2019)$. It has also been found that an altered mucosal barrier of the small intestine is a common factor regardless of IBS subtype (Gonzalez-Castro et al., 2017). This is not surprising since the small intestine bears a higher exposure to environmental antigens than the colon and is where most of the immune responses to digestive contents occur (Santaolalla et al., 2011). The impact of microbiota in the aetiology of IBS seems to start with dysbiosis, which in turn compromises integrity of the intestinal barrier, and ultimately affects immune modulation (Lacy et al., 2016; Simren et al., 2013). 
As already mentioned in previous sections, L. plantarum $299 \mathrm{v}$ has been shown to increase the microbiota diversity (Karlsson et al., 2010), promote intestinal barrier integrity through increasing mucin production (Dykstra et al., 2011; Mack et al., 1999, 2003), and increase the carboxylic acid concentration in faeces (Johansson et al., 1998). Moreover, L. plantarum 299v has also been shown to affect immunomodulatory responses in various models, as discussed in Section 3 - Inflammatory response. Several proinflammatory cytokines are thought to contribute to the pathogenesis of IBS (Mitselou et al., 2020; Vara et al., 2018). One of these, IFN- $\gamma$, has been shown to be increased in the mucosa of IBS patients irrespective of IBS type (Barbaro et al., 2016) and decreased by L. plantarum 299v in a mouse model of IBS (Waugh et al., 2009).

\section{Challenges with IBS studies}

Studies in subjects with IBS can be challenging due to the natural variation of the IBS symptoms over time and the large placebo effect related to the symptoms reported by the subjects. Many people suffering from IBS have had difficulties finding relevant professional consultation, treatment, and relief (Shah and Pimentel, 2014). Thus, the sheer participation in a clinical study focusing on IBS, with regular visits and study personnel showing an interest in the health status of the participant, may result in improved symptom scores by the subjects (McCarney et al., 2007). Due to these specific conditions, a relatively large number of participants is required to give statistically reliable results (Shah and Pimentel, 2014). The lack of positive results for some symptoms in the above-described studies may therefore be due to the relatively low numbers of participants included, such as for overall IBS symptoms (Sen et al., 2002; Stevenson et al., 2014) and abdominal pain (Nobaek et al., 2000).

Despite small differences in the settings and varied outcomes of different studies, they all point to an improvement of IBS symptoms by L. plantarum $299 \mathrm{v}$, especially abdominal pain and bloating as mentioned in other review articles assessing the efficacy of probiotics (Bixquert Jimenez, 2009; Hoveyda et al., 2009; McFarland et al., 2018; Sniffen et al., 2018; Zhang et al., 2016).

\section{Inflammatory bowel disease}

Inflammatory bowel disease (IBD) refers to chronic relapsing inflammation of the intestines and includes the disorders ulcerative colitis (UC) and Crohn's disease (CD). Symptoms of CD and UC are severe diarrhoea, abdominal pain, blood in stools, fatigue, and unintended weight loss, negatively affecting quality of life. UC causes ulcers in the colon and rectum, while the inflammation in $\mathrm{CD}$ affects primarily the small intestine.
The aetiology of IBD is not fully known but involves genetic, environmental, microbial, and immunological factors, described more in detail in the review by Zhang and $\mathrm{Li}$ (2014). The gut microbiome in IBD patients has been shown to be significantly less diverse than that of healthy controls (Joossens et al., 2011), however, it is unclear whether the changes in microbiota composition are part of the cause, or rather a consequence, of IBD. A recent review article suggests that defects in communication between the innate immunity and the mucosal barrier are more important for the pathophysiology of IBD than the acquired immune system (Stange and Schroeder, 2019). The authors suggest that targeting the gut bacteria could prevent the development of inflammation in IBD and would be a better approach than trying to dampen an already established inflammation.

L. plantarum 299v has been shown to reduce histological scores and cytokine levels associated with IBD in different colitis animal models (Osman et al., 2004; Schultz et al., 2002). Slight improvement of colonic, rectal and caecal histological scores and a lower production of the cytokines IL-12 and IFN- $\gamma$ were observed in IL-10 knockout mice with established colitis when treated with L. plantarum 299v for four weeks. However, when L. plantarum $299 \mathrm{v}$ was given as prevention, it did not show the same effectiveness (Schultz et al., 2002). L. plantarum 299v has also been shown to significantly improve disease activity index in rats with dextran sulphate sodium (DSS) induced colitis (Osman et al., 2004), but did not prevent relapse of colitis in a rat model under antibiotic treatment (Dieleman et al., 2003). Although DSS administration is commonly used to induce colitis in animal models, the method has its drawbacks since it does not directly cause intestinal inflammation but rather chemical injury to the epithelium, which in turn triggers inflammation. Hence, there are several different models to study acute colitis, but neither of them truly resembles the chronic changes observed in human IBD (Low et al., 2013).

Histological and immunological improvement in animal colitis models seems to agree with clinical studies. Patients with active UC taking oat gruel fermented with L. plantarum $299 \mathrm{v}$ significantly improved their symptoms during a 24-week intervention (Krag et al., 2012). The results were confirmed in a randomised study comparing a drink containing L. plantarum 299v to a similar product without bacteria (Krag et al., 2013).

The effects of L. plantarum 299v on symptoms of IBD seem to be partially explained by immune-related mechanisms and inhibition of translocation. Bacterial translocation induces inflammatory immune responses, which $L$. plantarum 299v has been shown to reduce in rats with enterocolitis (Mao et al., 1996a). The mucus layer in IBD patients is more permeable than in healthy controls, thus, the epithelial barrier is weakened (Johansson et al., 2014; 
Salim and Soderholm, 2011). As previously mentioned, L. plantarum 299v has been shown to promote mucus production (Mack et al., 1999, 2003), reduce translocation (Mangell et al., 2006), and strengthen tight junctions (Barnett et al., 2018), which may contribute to the beneficial effects on IBD symptoms.

Many IBD patients who suffer this chronic disease with a constant inflammation may have to undergo an intestinal resection during their lifetime (Sica and Biancone, 2013). Liu and colleagues studied the side-effects of external radiation on colonic anastomosis healing, and the impact of supplementation with L. plantarum $299 \mathrm{v}$, in a rat model. The results suggest that administration of $L$. plantarum $299 \mathrm{v}$ might reduce the inflammatory reaction, increase collagen deposition, and improve colonic anastomotic healing (Liu et al., 2001). Colonic anastomosis healing was also studied in rats fed either low fibre diet, normal chow, or normal chow with L. plantarum 299v. Compared to the low fibre diet, both normal chow and normal chow with $L$. plantarum 299v facilitated healing of colonic anastomosis (Mangiante et al., 2001b).

\section{Gastrointestinal infections}

The effects of L. plantarum 299v on the incidence, symptoms and recurrence of antibiotic associated diarrhoea (AAD) and gastrointestinal infections, such as $C$. difficile infection (CDI), have been investigated in several clinical studies.

\section{Antibiotic associated diarrhoea}

AAD is often defined as three or more loose to watery stools within $24 \mathrm{~h}$, starting after initiation of antibiotic treatment. Prevention of AAD is especially important in immunocompromised patients, for example after an organ transplantation, since diarrhoeal episodes can lead to reduced concentration of immunosuppressive agent in the blood, increasing the risk of acute rejection (Angarone and Ison, 2015).

L. plantarum $299 \mathrm{v}$ taken during antibiotic treatment reduced mild GI symptoms associated with antibiotic intake, such as loose/watery stools or nausea in adult patients (Lonnermark et al., 2010), but had lower efficiency in children (Olek et al., 2017). While the adult population included both hospitalised patients and outpatients, of which $45 \%$ were given antibiotics intravenously, the paediatric population was treated in primary healthcare settings due to infections of the respiratory tract, ear or urinary tract, and were otherwise healthy, which could explain the discrepancy of the probiotic efficiency in AAD. Furthermore, in these studies, the incidence of AAD was rather low compared to older studies (approximately $7 \%$ versus $16 \%$ and $3 \%$ versus $6 \%$ in adults and children, respectively (Asha et al., 2006; Damrongmanee and Ukarapol, 2007)), possibly due to different patterns of antibiotic use.

As previously mentioned, intake of L. plantarum $299 \mathrm{v}$ during antibiotic treatment also seems to help maintain the levels of butyric acid as well as total organic acids in comparison with placebo, which could indicate that $L$. plantarum $299 \mathrm{v}$ would help minimise disturbances to the microbiota during the course of antibiotic treatment (Wullt et al., 2007).

\section{Clostridioides difficile}

C. difficile is currently the most frequently identified pathogen involved in the development of AAD (Dudzicz et al., 2017). Infections by other microbes, such as Staphylococcus aureus and Clostridium perfringens have also been identified as causes (Boyce and Havill, 2005; Modi and Wilcox, 2001). C. difficile associated diarrhoea (CDAD) caused by CDI is associated with dysbiosis and occurs most frequently in patients under broad spectrum antibiotic therapy. The risk of CDI is increased in the elderly and patients with previous hospitalisations, comorbid conditions, or impaired immune system. CDAD does not necessarily occur due to the actual infection but rather to large clostridial toxins, that also cause inflammation and tissue necrosis. Thus, CDI is often diagnosed based on detection of these toxins in faeces. The cascades triggered by the toxins have been extensively reviewed by Smits and colleagues (2016).

Studies evaluating the efficacy of L. plantarum $299 \mathrm{v}$ for CDI prevention have shown promising results. A study by Wullt et al. (2003) demonstrated that $L$. plantarum $299 \mathrm{v}$ tended to reduce the incidence of recurrent CDI in adults. Prophylactic use of $L$. plantarum 299v significantly decreased CDI incidence in critically ill patients (Klarin et al., 2008): 19\% of the patients in the control group had a CDI compared to none in the L. plantarum $299 \mathrm{v}$ group. In another study performed over three twelvemonth periods, hospitalised patients under antibiotic and immunosuppressive therapy were given either $L$. plantarum 299v or other probiotic formulations (Dudzicz et al., 2018; Kujawa-Szewieczek et al., 2015). The other probiotic formulations were given during the first and third years and L. plantarum $299 \mathrm{v}$ was given during the second year. A significant reduction of CDI incidence in the ward was observed during the second year when L. plantarum $299 \mathrm{v}$ was administered, compared to the first year (KujawaSzewieczek et al., 2015), and the incidence of CDI increased again during the third year, after administration of $L$. plantarum 299v ceased (Dudzicz et al., 2018). Interestingly, although $L$. plantarum $299 \mathrm{v}$ was only given to the patients treated with antibiotic and immunosuppressive therapy, the number of CDI cases in the entire ward also decreased 
during the second year. Moreover, during the second year, fewer diarrheal days were reported than during the first year, when L. plantarum 299v was not administered (Kujawa-Szewieczek et al., 2015).

\section{Iron absorption}

Iron deficiency is the most common cause of anaemia and explains approximately $50 \%$ of all cases of anaemia worldwide. According to the World Health Organization (WHO), around 500 million women, more than 30 million pregnant women and almost 300 million children suffered from anaemia in 2011 (WHO, 2015). The need for iron varies depending on age, gender, and physical status, where children, women of fertile age, and pregnant or lactating women have higher needs.

The typical Western diet contains approximately $14 \mathrm{mg}$ of iron per 2,000 kcal (the average daily energy intake), but only 1-4 mg is absorbed (Weinborn et al., 2017). There are two forms of dietary iron: haem iron, found in animal sources, and non-haem iron, found in both animal and plant-based foods. The comprehensive review by Beck and colleagues (2014) describes how different dietary components interact with non-haem iron in the intestine impacting iron absorption. Soy protein, legumes, cereals, eggs, and dairy products are examples of foods that decrease iron absorption to some extent, and phytic acid and phenolic compounds (found in plant seeds, tea and coffee) are dietary factors that inhibit the absorption. On the other hand, vitamin C, naturally present in fruits and vegetables, increases iron absorption. When the iron uptake from food does not meet nutritional requirements, iron deficiency may develop. Iron supplements effectively reduce iron deficiency, and consequently the prevalence of anaemia, but are strongly associated with GI side effects, such as abdominal pain and constipation (Low et al., 2016). This is due to the high concentration of iron present in the supplements and the low absorption rate in the intestine that will lead to a high iron content in the colon. Moreover, growth and adhesion of pathogenic bacteria, such as Salmonella Typhimurium have been shown to increase in response to high intestinal iron levels (Kortman et al., 2012).

Insufficient iron levels is the most common micronutrient deficiency globally (Bailey et al., 2015; World Health Organization, 2020) and given the very common side effects of iron supplements, finding ways to increase iron absorption, rather than only increasing the intake of iron, would be desirable. One way of increasing iron absorption is by increasing iron bioavailability through fermentation of foods. Fermentation is believed to increase iron absorption by increasing ferric iron $\left(\mathrm{Fe}^{3+}\right)$ released from the food matrix (Bering et al., 2006; Scheers et al., 2016). In foods rich in phytic acid, such as some pseudo cereals, fermentation results in lower $\mathrm{pH}$, increasing the activity of the endogenous enzyme phytase, which in turn improves iron bioavailability (Castro-Alba et al., 2019). Added to the effect on food matrix, organic acids formed during fermentation may also prolong gastric emptying (Liljeberg and Björck, 1998), potentially increasing the exposure of iron to the intestinal epithelium (Salovaara et al., 2002, 2003), hence enabling increased absorption.

\section{Increased iron uptake independent of food matrix}

L. plantarum 299v has been shown to increase iron absorption in several clinical studies in women of childbearing age (Bering et al., 2006; Hoppe et al., 2015, 2017) and improve iron status in clinical (Axling et al., 2020, 2021; Korcok et al., 2018) and animal (Adiki et al., $2019)$ studies. The studies by Bering et al. $(2006,2007)$ and Hoppe et al. $(2015,2017)$ all made use of a double-isotope cross-over design method. The usage of this method is validated and generally accepted for the measurement of iron absorption. The order of the meals was randomised in the first study by Bering et al. (2006), but to avoid carry-over effects on the placebo meal after the intake of L. plantarum $299 \mathrm{v}$, the sequence was altered to 2 days with the control, followed by 2 days with $L$. plantarum 299v in the latter study by Bering et al. (2007) and the studies by Hoppe et al. $(2015,2017)$.

Bering and colleagues investigated the potential of $L$. plantarum $299 \mathrm{v}$ to increase absorption of non-haem iron in humans by comparing four different oat gruels (Bering et al., 2006). They found that oat gruel fermented with $L$. plantarum $299 \mathrm{v}$ significantly increased the absorption of iron from a test meal by $80 \%$, compared to oat gruels that were either pasteurised after fermentation, non-fermented with adjusted $\mathrm{pH}$, or contained added organic acids. In a follow-up study, Bering and colleagues compared the effect of a heat-inactivated fermented oat gruel with or without lyophilised L. plantarum $299 \mathrm{v}$ added to the cold gruel after pasteurisation (Bering et al., 2007). However, with this setup, no significant difference in iron absorption between the test products was observed, with the authors hypothesising that the bacteria 'were not in a comparable active state', compared to the previous study.

The positive results from the first study by Bering et al. (2006) were later confirmed in four different trials (two in each publication) with a fruit drink (Hoppe et al., 2015) and lyophilised bacteria in capsules (Hoppe et al., 2017). In the first study by Hoppe et al. (2015), different doses of $L$. plantarum $299 \mathrm{v}$ added to an iron and ascorbic acid supplemented fruit drink increased iron absorption compared to the same fruit drink without added bacteria. In the second study, lyophilised L. plantarum $299 \mathrm{v}$ with added iron, folic acid and ascorbic acid in capsules were used in two separate identical trials, both showing a significantly increased iron absorption from a light meal, 
compared to placebo (Hoppe et al., 2017). These results are in contrast with the study above by Bering et al. (2007), where the lyophilised bacteria were added directly to a heat-inactivated fermented oat gruel with a low $\mathrm{pH}$ caused by the fermentation. As discussed in the study by Bering et al. (2007), later experiments showed that the metabolic activity of $L$. plantarum $299 \mathrm{v}$ in this oat gruel at $37^{\circ} \mathrm{C}$ was delayed with approximately $1 \mathrm{~h}$. This could explain why no effect on the iron absorption was shown in this study. In the study by Hoppe et al. (2017), the lyophilised bacteria were encapsulated and protected from the low $\mathrm{pH}$ in the stomach. The bacteria were therefore probably in a more active state once released into the neutral environment in the duodenum where the iron absorption takes place. These results suggest that live L. plantarum $299 \mathrm{v}$ was responsible for the increase of iron absorption, rather than reduced $\mathrm{pH}$ or organic acids, which is in line with the studies by Scheers et al. (2016) and Bering et al. (2006). Effects on iron absorption have also been investigated for other probiotic strains (Skrypnik et al., 2019, 2020), however, the results suggest that the health-promoting effects on iron absorption described above may be a specific trait of L. plantarum 299v.

\section{Long-term effects on iron status}

Serum iron concentration rather than iron absorption was investigated in a small, exploratory study where lyophilised L. plantarum $299 \mathrm{v}$ combined with $10 \mathrm{mg}$ sucrosomial iron and $15 \mathrm{mg}$ of ascorbic acid were administered to healthy women of child-bearing age for 7 days and blood samples analysed 10-12 days after administration ceased. The study reported an $11 \%$ increase in serum iron concentration compared to the placebo group, however, it was underpowered, and no statistical analysis was shown (Korcok et al., 2018).

The long-term effects of $L$. plantarum $299 \mathrm{v}$ on improving serum ferritin levels have been investigated in healthy pregnant women (Axling et al., 2021) and in a group of healthy female athletes (Axling et al., 2020). The female athletes had low iron stores but were not anaemic and were randomised to receive either one capsule daily containing $20 \mathrm{mg}$ of iron (as ferrous fumarate) and L. plantarum 299v, or $20 \mathrm{mg}$ of iron alone (placebo) for 12 weeks. In the group receiving L. plantarum $299 \mathrm{v}$, plasma ferritin levels increased by $70 \%$, compared to $42 \%$ in the placebo group, although the difference was not statistically significant. The effect was apparent already after four weeks, with a close to significant difference between groups, in favour of L. plantarum 299v (Axling et al., 2020).

A population of 326 healthy, non-anaemic, pregnant women was studied in a prospective, multicentre trial. In this study, two capsules a day, one with each main meal, of placebo or lyophilised L. plantarum $299 \mathrm{v}$ with $4.2 \mathrm{mg}$ of iron, 12 $\mathrm{mg}$ ascorbic acid and $30 \mu \mathrm{g}$ folic acid were administered. The women received study product from gestational week 10-12 until the end of pregnancy, or until a potential need of conventional iron therapy. In the group receiving $L$. plantarum 299v, the pregnancy-related decreases in serum ferritin levels, total body iron status, and haemoglobin levels were mitigated, compared to the placebo group. Moreover, the study showed that supplementation with $L$. plantarum 299v, iron, ascorbic acid and folic acid resulted in reduced prevalence of iron deficiency and iron deficiency anaemia in late pregnancy (Axling et al., 2021). It can thus be hypothesised that this could delay or even prevent the need for traditional iron therapy during pregnancy.

\section{Potential mode of action}

The mechanism behind increased iron absorption driven by L. plantarum $299 \mathrm{v}$ needs to be further investigated, but it has been suggested that the effects are mediated via the $\mathrm{Fe}^{3+} /$ Duodenal cytochrome B (DcytB) axis (Sandberg et al., 2018). L. plantarum $299 \mathrm{v}$ increased the $\mathrm{Fe}^{3+}$ form of iron in a simulated GI digestion of a test meal with capsules, oat drinks or fruit drinks, compared to samples without the bacteria. In the same study, human intestinal co-cultures of enterocytes and goblet cells (Caco-2/HT29 MTX cells) had higher levels of the ferric reductase DcytB in the presence of L. plantarum 299v, while the levels of the ferrous iron $\left(\mathrm{Fe}^{2+}\right)$ importer, the divalent metal ion transporter 1 (DMT1), were not affected. This increase in DcytB seems to be a response to the increased ferric iron made available by $L$. plantarum $299 \mathrm{v}$ and not a direct effect of $L$. plantarum $299 \mathrm{v}$.

Bering and colleagues (2007) showed that there is no absorption of iron in the distal intestine. The reduction of $\mathrm{Fe}^{3+}$ to $\mathrm{Fe}^{2+}$ required for uptake via DMT1 takes place in the duodenum, which suggests that L. plantarum $299 \mathrm{v}$ must be active in the most proximal small intestine to have an impact on iron absorption. Lyophilised bacteria are in a resting state and need to be rehydrated to become active, in contrast to the already active bacteria in the oat gruel and fruit drinks used in the studies by Bering et al. (2006) and Hoppe et al. (2015), respectively. The difference between the active and resting (lyophilised) bacteria in food and capsules may explain why more iron was absorbed with fruit drinks (Hoppe et al., 2015) than with capsules (Hoppe et al., 2017).

When evaluating the effect of $L$. plantarum $299 \mathrm{v}$ on iron absorption, the amount of iron seems to be an important factor. High doses of iron, like those found in conventional iron supplements, may result in no further increase of iron absorption by L. plantarum 299v for two main reasons: iron self-regulation mechanisms, and the presumed role of L. plantarum $299 \mathrm{v}$ to increase iron availability rather than absorption itself. Firstly, supplementation of iron increases the levels of hepcidin (a protein that helps regulate 
the uptake of iron), resulting in a decreased potential to absorb iron (Moretti et al., 2015). Secondly, since $L$. plantarum $299 \mathrm{v}$ seems to primarily increase availability of iron from the food matrix (Sandberg et al., 2018), the bacteria would not be able to further increase iron absorption when a high load of iron is already available. This could be a potential explanation of the results in the study by Rosen and colleagues in which $L$. plantarum $299 \mathrm{v}$ was administered together with iron and ascorbic acid to iron-deficient children for 6-8 weeks (Rosen et $a l ., 2019)$. The iron supplementation was dependent on the weight of the children $(3 \mathrm{mg} / \mathrm{kg})$ up to a maximum of $65 \mathrm{mg}$ /day in both the placebo and L. plantarum 299v groups. Although considered a low dose by the authors, the amount of iron administered in the study is high compared to the recommended daily intake for this age group (5-18 years; 11-13 mg per day (EFSA Panel on Dietetic Products and Allergies, 2015)). Naturally, ferritin levels increased significantly in both groups (slightly more in the probiotic group) and were positively correlated with the amount of iron administered. Although hepcidin levels were not measured in the study, it can be hypothesised that the high iron doses might have caused an increase in hepcidin preventing further iron absorption, and therefore the possibility for $L$. plantarum $299 \mathrm{v}$ to additionally increase iron uptake and consequently ferritin levels would be low.

The same reasoning as above regarding iron limiting the effect of L. plantarum $299 \mathrm{v}$ on iron absorption might also explain the rather small difference seen between the groups of athletes in the study referred to above (Axling et al., 2020), and could suggest that a lower dose of supplementary iron could have resulted in a more pronounced effect in the probiotic group. Taking into account the possible harmful side effects of high-dose iron supplements, L. plantarum $299 \mathrm{v}$ could be considered a novel strategy to safely increase iron uptake and potentially prevent iron deficiency without the side effects.

\section{Other indications}

L. plantarum 299v has been used to investigate the effects on other indications as well, such as psychological or mental health (the so-called gut-brain axis), metabolic health and oral health. Moreover, L. plantarum 299v has been used in various food applications.

\section{Gut-brain axis}

In recent years, the interest in how GI health may affect psychological health has increased. A disturbed GI microbial balance and decreased bacterial diversity have been coupled to mental health in several conditions (such as Parkinson's, Alzheimer's, major depression and autism spectrum disorders) (Cheng et al., 2019). Moreover, animal experiments have shown that mental stress increases the transepithelial permeability and translocation, and that probiotic administration can ameliorate bacterial translocation and reduce levels of stress hormones (Gareau et al., 2007).

L. plantarum 299v has been used in two clinical studies in the area of mental health. The first study including 41 students with an upcoming school exam showed that intake of $L$. plantarum $299 \mathrm{v}$ for two weeks significantly decreased saliva cortisol, compared to placebo (Andersson et al., 2016). The second study investigated the effect of cognitive function and biochemical parameters in subjects suffering from major depression. L. plantarum 299v or placebo was given to 60 subjects, all undergoing treatment with selective serotonin reuptake inhibitors, for a period of 8 weeks. The probiotic intake significantly improved cognitive performance, compared to placebo (Rudzki et al., 2019).

\section{Metabolic health}

The GI microbiota has been shown to have a direct role in human metabolic regulation through various types of interactions between the bacteria and the host. Dysbiosis and reduced bacterial diversity, as well as increased transepithelial permeability, have also been shown to be related to metabolic health (Boulange et al., 2016). $L$. plantarum 299v has been shown to affect certain factors coupled to metabolic health, including postprandial insulin responses, concentration of blood lipids and endothelial function (Bukowska et al., 1998; Granfeldt and Bjorck, 2011; Malik et al., 2018; Naruszewicz et al., 2002; Xu et al., 2018). Two meal studies, each including 11 healthy subjects, investigated the effect of beverages composed of different berries and fruits as well as oatmeal fermented with L. plantarum 299v on postprandial glucose and insulin responses. Both studies found that the beverages resulted in decreased insulin responses but had no effect on the glycaemic response compared to reference bread or a glucose drink (Granfeldt and Bjorck, 2011; Xu et al., 2018). Another meal study investigated the effect of barley kernels on blood glucose regulation and appetite regulating hormones with or without supplementation of different probiotics, including L. plantarum $299 \mathrm{v}$. The results showed that probiotic intake for 14 days increased the plasma levels of glucagon-like peptide 2 (Nilsson et al., 2016), a peptide which has been shown to improve intestinal integrity (Cani et al., 2009), after a standardised breakfast.

Ischaemic heart disease and stroke are the top two causes of death globally (WHO, 2018). Atherosclerotic dysfunctions are strongly associated with these diseases, and the risk for atherosclerosis is mediated by, among others, blood lipid profiles, blood pressure, fibrinogen levels and vascular endothelial function. In recent years there has been a growing interest in the possible effect of probiotics on metabolic parameters, and to date five studies 
have investigated the potential use of L. plantarum $299 \mathrm{v}$. Three of these were clinical studies with L. plantarum $299 v$ supplementation in fruit drinks for six weeks. The first study included 30 men with moderately elevated cholesterol levels. The probiotic group showed significantly reduced total and low-density lipoprotein cholesterol levels, as well as decreased fibrinogen levels compared to baseline, while no changes were seen in the placebo group (Bukowska et al., 1998). In the second study, 36 smokers were included, both men and women. Intake of L. plantarum 299v significantly reduced the systolic blood pressure, leptin, fibrinogen, and IL-6 levels, while no effects were seen in the placebo group. Moreover, the adhesion of monocytes, isolated from the subjects, to native and stimulated human umbilical vein endothelial cells was significantly reduced in the probiotic group, suggesting an impact on atherosclerotic plaque formation (Naruszewicz et al., 2002). In the third clinical study all 20 men with stable coronary artery disease received the probiotic drink; hence, the study was not placebo controlled. Supplementation resulted in a significantly improved brachial artery flowmediated dilation and decreased circulating levels of IL-8, IL-12, and leptin (Malik et al., 2018).

In addition to the three clinical studies summarised above, two animal studies investigating effects of L. plantarum $299 \mathrm{v}$ on ischaemia/reperfusion have been done. The first study was a rat model of myocardial infarction after antibiotic-induced intestinal dysbiosis. Supplementation of L. plantarum $299 \mathrm{v}$ for 14 days before induced ischaemia/ reperfusion resulted in decreased circulating leptin, smaller myocardial infarcts, and better recovery of mechanical function, compared to control (Lam et al., 2012). In the second study, ischaemia/reperfusion injury was induced in mice supplemented with both L. plantarum 299v and rosehip. The combination of rosehip and L. plantarum $299 \mathrm{v}$ reduced lipid peroxidation, however, the effect seemed to be primarily coming from rosehip, rather than L. plantarum 299v (Hakansson et al., 2006).

\section{Oral health}

Oral health, and more precisely dental plaque development, caries, and lesions, can be affected by the oral microbial composition. Probiotic bacteria for oral health promotion should be able to attach to the oral mucosa and dental tissues to become a part of an oral biofilm and compete with the growth of oral pathogens (such as Streptococcus mutans and Candida albicans). L. plantarum 299v has been investigated for usage in oral formulations in several studies. Different oromucosal delivery formats have also been investigated, with promising results (Hoffmann and Daniels, 2018; Pandey et al., 2016). Independently of the administration mode (from gargling of oat-gruel to drinking a fruit juice), L. plantarum $299 \mathrm{v}$ was found to attach to the human tonsillar surface and remain for up to
$8 \mathrm{~h}$ (Stjernquist-Desatnik et al., 2000). Binding-capacity of L. plantarum $299 \mathrm{v}$ to saliva-coated surfaces in vitro and survival of the strain in saliva after a $24 \mathrm{~h}$ incubation period have been shown (Haukioja et al., 2006). In vitro studies have demonstrated L. plantarum $299 \mathrm{v}$ to co-aggregate with selected oral pathogens to form a biofilm (Twetman et al., 2009), inhibit salivary mutant streptococci biofilm, and affect the pathogenesis of dental caries (Soderling et al., 2011). L. plantarum 299v also completely inhibited growth of all five mutant streptococci strains tested, and reduced the growth of C. albicans almost completely (Hasslof et al., 2010).

The production of lactic acid and subsequent reduction in $\mathrm{pH}$ is a beneficial trait in the GI tract but could be a negative effect in the oral cavity since a low $\mathrm{pH}$ could lead to progression of dental caries. L. plantarum $299 \mathrm{v}$ has been found to significantly decrease $\mathrm{pH}$ levels after incubation with different sugars and sweeteners (Haukioja et al., 2008; Hedberg et al., 2008; Keller and Twetman, 2012). Additional studies are needed to further elucidate the potential usage of L. plantarum $299 \mathrm{v}$ for improved oral health, despite its $\mathrm{pH}$-lowering effects.

\section{Various food applications}

The first food application for L. plantarum 299v was a fermented oat-meal beverage, developed as a new concept for enteral feeding. The formulation of this beverage was later optimised by Marklinder et al. regarding $\mathrm{pH}$, viability of the strain as well as addition of phytase to not interfere with iron and zinc absorption (Marklinder and Johansson, 1995; Marklinder and Lönner, 1994; Marklinder et al., 1995). The fermented oat-meal beverage is still used in the production of the fruit beverages ProViva ${ }^{\circledR}$ and GoodBelly ${ }^{\oplus}$ (Molin, 1994). ProViva ${ }^{\circledR}$ is often administered to patients in hospitals in Sweden and the rosehip-based drink was used in a study investigating tablet dissolution. Rosehip, rather than L. plantarum 299v, explained the slow dissolution of paracetamol tablets seen in the study (Akerman and Edvinsson, 2009).

Over the years, the general interest in probiotics has increased and L. plantarum $299 \mathrm{v}$ has been used in various applications related to food production. Already in 1995, Marklinder et al. showed that L. plantarum 299v could be used as a starter culture for production of barley sour dough (Marklinder and Johansson, 1995). Probiotic pineapple juice (Nguyen et al., 2019) and orange juice (Barbosa et al., 2015), quinoa juice (Canaviri Paz et al., 2020), legume sprouts (Swieca et al., 2018, 2019, 2020), fermented cauliflower and white beans (Thompson et al., 2020), dark chocolate (Mirkovic et al., 2018), bovine salami (Blaiotta et al., 2018) and button mushroom fruiting bodies (Jablonska-Rys et al., 2016) are other examples of food products where $L$. plantarum 299v has been used as either fermenter or simply 
added to obtain a probiotic food product. Good viability of the probiotic bacteria has been obtained in all the abovementioned studies.

Other studies have used L. plantarum 299v to obtain secondary metabolites, such as potentially antihypertensive peptides from fermented pea seeds (Jakubczyk et al., 2013), and to metabolise theaflavins from black tea to smaller, more bioavailable, polyphenols (Chen et al., 2012). When used together with adzuki and mung bean sprouts, higher antioxidant capacity and especially cytotoxic and cytostatic activity against human gastric cancer cells were observed (Świeca et al., 2020). L. plantarum 299v was found to successfully produce volatile sulphur compounds, important for food flavouring and aroma, from cysteine and methionine (Sreekumar et al., 2009). Moreover, studies have shown that L. plantarum $299 \mathrm{v}$ is able to grow on different prebiotic substrates, for example galacto-oligosaccharides produced from whey permeate (Golowczyc et al., 2013) and short-chain fructo-oligosaccharides (Saulnier et al., 2008). L. plantarum 299v has also been evaluated in combination with a microalga (Chlorella sorokiniana) in a dairy product (flan), where it showed anti-microbial effects against rotavirus (Cantu-Bernal et al., 2020). L. plantarum 299v incorporated in animal feed resulted in reduced oxidative stress, increased antioxidant capacity and improved growth rate of chickens (Khanian et al., 2019), as well as improved fish performance in Atlantic salmon (Rodriguez et al., 2020).

The viability of L. plantarum strains in calcium alginate beads has been found to be improved when whey proteins were used as coating material during encapsulation (Gbassi et al., 2009). Successful co-delivery of bioactive hydroxytyrosol from a standardised extract of Olea europaea leaves (olive leaves) with L. plantarum 299v has been shown using novel food-grade granules (Aponte $e t$ al., 2018). Another possible application for L. plantarum $299 \mathrm{v}$ is the preservation of cereal crops, as Zhao et al. (2017) showed that the strain possesses anti-Fusarium activity. More recently, L. plantarum 299v was found to successfully catalyse the hydration reaction of the most commonly consumed unsaturated fatty acids; oleic, linoleic, and linolenic acids (Serra et al., 2020). This may be interesting for the food industry, since using probiotics to stabilise various food applications, such as emulsions, is not very common today.

L. plantarum 299v, being a well-known and characterised probiotic strain, has also been used as a positive control in various studies. One example is the study by CastroRodríguez et al. (2015) who used L. plantarum 299v to compare the viability and probiotic potential of strains found in agave, a component of a Mexican beverage (pulque). Gotteland et al. (2014) used L. plantarum 299v as a positive control for a safety evaluation of bacterial strains found in human breast milk, faeces, and goat cheese. Melgar-Lalanne et al. (2013) used L. plantarum 299v and Lacticaseibacillus casei Shirota as comparisons to halotolerant lactobacilli isolated from ripened tropical Mexican cheese.

\section{Conclusions}

L. plantarum $299 \mathrm{v}$ was first discovered as a healthsupporting probiotic strain more than 30 years ago and continues to be extensively researched around the world. This review aimed to describe and discuss all published research studies (up until June 2020) concerning the effects of L. plantarum $299 \mathrm{v}$. In vitro and animal studies have helped to better understand various characteristics of this strain and reveal potential modes of action for many promising results obtained in clinical studies. It is important to remember that probiotics are not pharmaceutical drugs but are intended to support and help maintain health or be used for preventative purposes. Despite this, intake of L. plantarum $299 \mathrm{v}$ has been shown to provide relief of symptoms for those suffering from IBS and IBD and to mitigate iron deficiency.

IBS is the most commonly reported GI disorder globally. Repeated studies have shown that intake of L. plantarum $299 \mathrm{v}$ results in decreased severity and intensity of IBS symptoms such as abdominal pain, flatulence, bowel habits and bloating. Moreover, intake of L. plantarum $299 \mathrm{v}$ has been shown to increase bacterial diversity in the intestine, provide relief for those suffering from IBD, as well as decrease the incidence of CDI for those prescribed antibiotics.

Iron deficiency explains approximately $50 \%$ of all cases of anaemia worldwide and is often caused by poor iron absorption. Traditionally, iron supplementation is used as treatment of iron deficiency. However, L. plantarum 299v has been shown to significantly increase iron absorption, likely due to an increase in iron bioavailability, and recently to improve long-term iron status in healthy female athletes and non-anaemic pregnant women. These results suggest that L. plantarum $299 \mathrm{v}$ is a novel approach to preventing iron deficiency and iron deficiency anaemia.

The World Health Organization (WHO) classifies probiotics as 'live microorganisms which when administered in adequate amounts confer a health benefit on the host' and additional requirements have been described recently (Binda et al., 2020). The bacterial strain L. plantarum $299 \mathrm{v}$ is well characterised, has a clinically proven dosage and has been shown to support health for a broad range of indications. Since the 1990s, L. plantarum 299v has been incorporated in functional food products and food supplements in more than 40 markets worldwide. 
To conclude the various effects of L. plantarum 299v described herein, studies have shown the safety of use, survival through the GI tract, binding mechanism, and robust effects for improved human health of this strain. Intake of L. plantarum 299v has been shown to affect pathogen inhibition, intestinal barrier function, and the immune system. The to date more than 60 published human clinical studies performed with L. plantarum 299v have demonstrated several health benefits, where the strongest evidence for the effectiveness is within gastrointestinal health and iron absorption.

\section{Conflict of interest}

The strain L. plantarum $299 \mathrm{v}, \mathrm{LP}^{2} 99 \mathrm{~V}^{\circledR}$ is proprietary to Probi AB, Sweden. EAN, CT, CM and NL are employed by Probi AB. BJ is a senior scientific advisor to Probi AB.

\section{References}

Adawi, D., Ahrne, S. and Molin, G., 2001. Effects of different probiotic strains of Lactobacillus and Bifidobacterium on bacterial translocation and liver injury in an acute liver injury model. International Journal of Food Microbiology 70: 213-220.

Adawi, D., Kasravi, F.B., Molin, G. and Jeppsson, B., 1997. Effect of Lactobacillus supplementation with and without arginine on liver damage and bacterial translocation in an acute liver injury model in the rat. Hepatology 25: 642-647. https://doi.org/10.1002/ hep.510250325

Adawi, D., Molin, G. and Jeppsson, B., 1998. Inhibition of nitric oxide production and the effects of arginine and Lactobacillus administration in an acute liver injury model. Annals of Surgery 228: 748-755. https://doi.org/10.1097/00000658-199812000-00005

Adawi, D., Molin, G., Ahrné, S. and Jeppsson, B., 2002. Safety of the probiotic strain Lactobacillus plantarum DSM 9843 (=strain 299v) in an Endocarditis animal model. Microbial Ecology in Health and Disease 14: 50-53. https://doi.org/10.1080/089106002760002766

Adiki, S.K., Perla, C.K., Saha, G., Katakam, P. and Theendra, V., 2019. Enhancement in iron absorption on intake of chemometrically optimized ratio of probiotic strain Lactobacillus plantarum 299v with iron supplement pearl millet. Biological Trace Element Research 190: 150-156.

Adlerberth, I., Ahrne, S., Johansson, M.L., Molin, G., Hanson, L.A. and Wold, A.E., 1996. A mannose-specific adherence mechanism in Lactobacillus plantarum conferring binding to the human colonic cell line HT-29. Applied and Environmental Microbiology 62: 22442251.

Ahrne, S. and Hagslatt, M.L., 2011. Effect of lactobacilli on paracellular permeability in the gut. Nutrients 3: 104-117. https://doi. org/10.3390/nu3010104

Ahrné, S., Nobaek, S., Jeppsson, B., Adlerberth, I., Wold, A.E. and Molin, G., 1998. The normal Lactobacillus flora of healthy human rectal and oral mucosa. Journal of Applied Microbiology 85: 88-94.
Akerman, U. and Edvinsson, L., 2009. Influence of fruit drinks with or without Lactobacillus Lp299v on the gastrointestinal uptake of paracetamol in man. BMC Research Notes 2: 45. https://doi. org/10.1186/1756-0500-2-45

Anderson, R.C., Cookson, A.L., McNabb, W.C., Kelly, W.J. and Roy, N.C., 2010. Lactobacillus plantarum DSM 2648 is a potential probiotic that enhances intestinal barrier function. FEMS Microbiology Letters 309: 184-192.

Andersson, H., Tullberg, C., Ahrne, S., Hamberg, K., Lazou Ahren, I., Molin, G., Sonesson, M. and Hakansson, A., 2016. Oral administration of Lactobacillus plantarum 299v reduces cortisol levels in human saliva during examination induced stress: a randomized, double-blind controlled trial. International Journal of Microbiology 2016: 8469018. https://doi.org/10.1155/2016/8469018

Angarone, M. and Ison, M.G., 2015. Diarrhea in solid organ transplant recipients. Current Opinion in Infectious Diseases 28: 308-316.

Aponte, M., Ungaro, F., d'Angelo, I., De Caro, C., Russo, R., Blaiotta, G., Dal Piaz, F., Calignano, A. and Miro, A., 2018. Improving in vivo conversion of oleuropein into hydroxytyrosol by oral granules containing probiotic Lactobacillus plantarum 299v and an Olea europaea standardized extract. International Journal of Pharmaceutics 543: 73-82. https://doi.org/10.1016/j. ijpharm.2018.03.013

Asha, N.J., Tompkins, D. and Wilcox, M.H., 2006. Comparative analysis of prevalence, risk factors, and molecular epidemiology of antibiotic-associated diarrhea due to Clostridium difficile, Clostridium perfringens, and Staphylococcus aureus. Journal of Clinical Microbiology 44: 2785-2791. https://doi.org/10.1128/ JCM.00165-06

Axling, U., Önning, G., Combs, M.A., Bogale, A., Högström, M. and Svensson, M., 2020. The effect of Lactobacillus plantarum 299v on iron status and physical performance in female iron-deficient athletes: a randomized controlled trial. Nutrients 12: 1279.

Axling, U., Önning, G., Martinsson Niskanen, T., Larsson, N., Hansson, S.R. and Hulthén, L., 2021. The effect of Lactiplantibacillus plantarum $299 \mathrm{v}$ together with a low dose of iron on iron status in healthy pregnant women: a randomized clinical trial. Acta Obstetricia et Gynecologica Scandinavica 100, volume 9: 16021610. https://doi.org/10.1111/aogs.14153

Azad, M.A.K., Sarker, M. and Wan, D., 2018. Immunomodulatory effects of probiotics on cytokine profiles. Biomed Research International, Article ID: 8063647.

Badger, S.A., Jones, C., Regan, M., Diamond, T., Parks, R.W. and Taylor, M.A., 2013. Modulation of the hepatic cytokine response to portal endotoxaemia using the probiotic Lactobacillus plantarum 299v. Journal of Gastroenterology and Hepatology Research 2: 632-637. https://doi.org/10.6051/j.issn.2224-3992.2013.02.290

Bailey, R.L., West Jr, K.P. and Black, R.E., 2015. The epidemiology of global micronutrient deficiencies. Annals of Nutrition and Metabolism 66, Suppl. 2: 22-33. https://doi.org/10.1159/000371618 Barbaro, M.R., Di Sabatino, A., Cremon, C., Giuffrida, P., Fiorentino, M., Altimari, A., Bellacosa, L., Stanghellini, V. and Barbara, G., 2016. Interferon-gamma is increased in the gut of patients with irritable bowel syndrome and modulates serotonin metabolism. American Journal of Physiology - Gastrointestinal and Liver Physiology 310: G439-G447. https://doi.org/10.1152/ajpgi.00368.2015 
Barbosa, J., Borges, S. and Teixeira, P., 2015. Influence of sub-lethal stresses on the survival of lactic acid bacteria after spray-drying in orange juice. Food Microbiology 52: 77-83. https://doi.org/10.1016/j. fm.2015.06.010

Barnett, A.M., Roy, N.C., Cookson, A.L. and McNabb, W.C., 2018. Metabolism of caprine milk carbohydrates by probiotic bacteria and Caco-2:HT29(-)MTX epithelial co-cultures and their impact on intestinal barrier integrity. Nutrients 10: 949 . https://doi. org/10.3390/nu10070949

Bauerl, C., Llopis, M., Antolin, M., Monedero, V., Mata, M., Zuniga, M., Guarner, F. and Perez Martinez, G., 2013. Lactobacillus paracasei and Lactobacillus plantarum strains downregulate proinflammatory genes in an ex vivo system of cultured human colonic mucosa. Genes and Nutrition 8: 165-180. https://doi.org/10.1007/s12263012-0301-y

Beck, H.C., Madsen, S.M., Glenting, J., Petersen, J., Israelsen, H., Norrelykke, M.R., Antonsson, M. and Hansen, A.M., 2009. Proteomic analysis of cell surface-associated proteins from probiotic Lactobacillus plantarum. FEMS Microbiology Letters 297: 61-66. https://doi.org/10.1111/j.1574-6968.2009.01662.x

Beck, K.L., Conlon, C.A., Kruger, R. and Coad, J., 2014. Dietary determinants of and possible solutions to iron deficiency for young women living in industrialized countries: a review. Nutrients 6: 3747-3776. https://doi.org/10.3390/nu6093747

Berggren, A., Söderberg, L., Önning, G., Hagslätt, M.-L.J. and Axelsson, I., 2003. Intestinal function, microflora and nutrient intake of children after administration of a fermented oat product containing Lactobacillus plantarum DSM 9843 (299v). Microbial Ecology in Health and Disease 15: 160-168. https://doi. org/10.1080/08910600410024825

Bering, S., Sjoltov, L., Wrisberg, S.S., Berggren, A., Alenfall, J., Jensen, M., Hojgaard, L., Tetens, I. and Bukhave, K., 2007. Viable, lyophilized lactobacilli do not increase iron absorption from a lactic acidfermented meal in healthy young women, and no iron absorption occurs in the distal intestine. British Journal of Nutrition 98: 991997. https://doi.org/10.1017/S0007114507761809

Bering, S., Suchdev, S., Sjoltov, L., Berggren, A., Tetens, I. and Bukhave, K., 2006. A lactic acid-fermented oat gruel increases non-haem iron absorption from a phytate-rich meal in healthy women of childbearing age. British Journal of Nutrition 96: 80-85. https:// doi.org/10.1079/bjn20061683

Binda, S., Hill, C., Johansen, E., Obis, D., Pot, B., Sanders, M.E., Tremblay, A. and Ouwehand, A.C., 2020. Criteria to qualify microorganisms as 'probiotic' in foods and dietary supplements. Frontiers in Microbiology 11: 1662. https://doi.org/10.3389/ fmicb.2020.01662

Bixquert Jimenez, M., 2009. Treatment of irritable bowel syndrome with probiotics. An etiopathogenic approach at last? Revista Española de Enfermedades Digestivas 101: 553-564. https://doi. org/10.4321/s1130-01082009000800006

Blaiotta, G., Murru, N., Di Cerbo, A., Romano, R. and Aponte, M., 2018. Production of probiotic bovine salami using Lactobacillus plantarum 299v as adjunct. Journal of the Science of Food and Agriculture 98: 2285-2294. https://doi.org/10.1002/jsfa.8717
Boulange, C.L., Neves, A.L., Chilloux, J., Nicholson, J.K. and Dumas, M.E., 2016. Impact of the gut microbiota on inflammation, obesity, and metabolic disease. Genome Medicine 8: 42. https://doi. org/10.1186/s13073-016-0303-2

Bourriaud, C., Robins, R.J., Martin, L., Kozlowski, F., Tenailleau, E., Cherbut, C. and Michel, C., 2005. Lactate is mainly fermented to butyrate by human intestinal microfloras but inter-individual variation is evident. Journal of Applied Microbiology 99: 201-212. https://doi.org/10.1111/j.1365-2672.2005.02605.x

Boyce, J.M. and Havill, N.L., 2005. Nosocomial antibiotic-associated diarrhea associated with enterotoxin-producing strains of methicillin-resistant Staphylococcus aureus. American Journal of Gastroenterology 100: 1828-1834. https://doi.org/10.1111/j.15720241.2005.41510.x

Bukowska, H., Pieczul-Mroz, J., Jastrzebska, M., Chelstowski, K. and Naruszewicz, M., 1998. Decrease in fibrinogen and LDL-cholesterol levels upon supplementation of diet with Lactobacillus plantarum in subjects with moderately elevated cholesterol. Atherosclerosis 137: 437-438. https://doi.org/10.1016/s0021-9150(97)00283-9

Buntin, N., De Vos, W.M. and Hongpattarakere, T., 2017. Variation of mucin adhesion, cell surface characteristics, and molecular mechanisms among Lactobacillus plantarum isolated from different habitats. Applied Microbiology and Biotechnology 101: 7663-7674. https://doi.org/10.1007/s00253-017-8482-3

Canavan, C., West, J. and Card, T., 2014. The epidemiology of irritable bowel syndrome. Clinical Epidemiology 6: 71-80. https://doi. org/10.2147/CLEP.S40245

Canaviri Paz, P., Janny, R.J. and Håkansson, Å., 2020. Safeguarding of quinoa beverage production by fermentation with Lactobacillus plantarum DSM 9843. International Journal of Food Microbiology 324: 108630. https://doi.org/10.1016/j.ijfoodmicro.2020.108630

Cani, P.D., Possemiers, S., Van de Wiele, T., Guiot, Y., Everard, A., Rottier, O., Geurts, L., Naslain, D., Neyrinck, A., Lambert, D.M., Muccioli, G.G. and Delzenne, N.M., 2009. Changes in gut microbiota control inflammation in obese mice through a mechanism involving GLP-2-driven improvement of gut permeability. Gut 58: 1091-1103. https://doi.org/10.1136/gut.2008.165886

Cantu-Bernal, S., Dominguez-Gamez, M., Medina-Peraza, I., ArosUzarraga, E., Ontiveros, N., Flores-Mendoza, L., Gomez-Flores, R., Tamez-Guerra, P. and Gonzalez-Ochoa, G., 2020. Enhanced viability and anti-rotavirus effect of Bifidobacterium longum and Lactobacillus plantarum in combination with Chlorella sorokiniana in a dairy product. Frontiers in Microbiology 11: 875. https://doi. org/10.3389/fmicb.2020.00875

Castro-Alba, V., Lazarte, C.E., Perez-Rea, D., Carlsson, N.G., Almgren, A., Bergenståhl, B. and Granfeldt, Y., 2019. Fermentation of pseudocereals quinoa, canihua, and amaranth to improve mineral accessibility through degradation of phytate. Journal of the Science of Food and Agriculture 99: 5239-5248.

Castro-Rodríguez, D., Hernández-Sánchez, H. and Yáñez Fernández, J., 2015. Probiotic properties of Leuconostoc mesenteroides isolated from aguamiel of Agave salmiana. Probiotics and Antimicrobial Proteins 7: 107-117. https://doi.org/10.1007/s12602-015-9187-5

Chaplin, D.D., 2010. Overview of the immune response. Journal of Allergy and Clinical Immunology 125: S3-23. https://doi. org/10.1016/j.jaci.2009.12.980 
Chen, H., Hayek, S., Rivera Guzman, J., Gillitt, N.D., Ibrahim, S.A., Jobin, C. and Sang, S., 2012. The microbiota is essential for the generation of black tea theaflavins-derived metabolites. PLoS ONE 7: e51001. https://doi.org/10.1371/journal.pone.0051001

Cheng, L.H., Liu, Y.W., Wu, C.C., Wang, S. and Tsai, Y.C., 2019. Psychobiotics in mental health, neurodegenerative and neurodevelopmental disorders. Journal of Food and Drug Analysis 27: 632-648. https://doi.org/10.1016/j.jfda.2019.01.002

Christensen, H.R., Frokiaer, H. and Pestka, J.J., 2002. Lactobacilli differentially modulate expression of cytokines and maturation surface markers in murine dendritic cells. Journal of Immunology 168: 171-178. https://doi.org/10.4049/jimmunol.168.1.171

Cunningham-Rundles, S., Ahrne, S., Bengmark, S., Johann-Liang, R., Marshall, F., Metakis, L., Califano, C., Dunn, A.M., Grassey, C., Hinds, G. and Cervia, J., 2000. Probiotics and immune response. American Journal of Gastroenterology 95: S22-25. https://doi. org/10.1016/s0002-9270(99)00813-8

Cunningham-Rundles, S., Ahrne, S., Johann-Liang, R., Abuav, R., Dunn-Navarra, A.M., Grassey, C., Bengmark, S. and Cervia, J.S., 2011. Effect of probiotic bacteria on microbial host defense, growth, and immune function in human immunodeficiency virus type-1 infection. Nutrients 3: 1042-1070. https://doi.org/10.3390/ nu3121042

Damrongmanee, A. and Ukarapol, N., 2007. Incidence of antibioticassociated diarrhea in a pediatric ambulatory care setting. Journal of the Medical Association of Thailand 90: 513-517.

Dieleman, L.A., Goerres, M.S., Arends, A., Sprengers, D., Torrice, C., Hoentjen, F., Grenther, W.B. and Sartor, R.B., 2003. Lactobacillus GG prevents recurrence of colitis in HLA-B27 transgenic rats after antibiotic treatment. Gut 52: 370-376. https://doi.org/10.1136/ gut.52.3.370

Drossman, D.A. and Hasler, W.L., 2016. Rome IV-functional GI disorders: disorders of gut-brain interaction. Gastroenterology 150: 1257-1261.

Ducrotte, P., Sawant, P. and Jayanthi, V., 2012. Clinical trial: Lactobacillus plantarum 299v (DSM 9843) improves symptoms of irritable bowel syndrome. World Journal of Gastroenterology 18: 4012-4018. https://doi.org/10.3748/wjg.v18.i30.4012

Dudzicz, S., Adamczak, M. and Wiecek, A., 2017. Clostridium difficile infection in the nephrology ward. Kidney and Blood Pressure Research 42: 844-852. https://doi.org/10.1159/000484428

Dudzicz, S., Kujawa-Szewieczek, A., Kwiecien, K., Wiecek, A. and Adamczak, M., 2018. Lactobacillus plantarum 299v reduces the incidence of Clostridium difficile infection in nephrology and transplantation ward-results of one year extended study. Nutrients 10: 1574. https://doi.org/10.3390/nu10111574

Dykstra, N.S., Hyde, L., Adawi, D., Kulik, D., Ahrne, S., Molin, G., Jeppsson, B., Mackenzie, A. and Mack, D.R., 2011. Pulse probiotic administration induces repeated small intestinal Muc3 expression in rats. Pediatric Research 69: 206-211. https://doi.org/10.1203/ PDR.0b013e3182096ff0

European Food Safety Authority (EFSA), 2015. Scientific Opinion on dietary reference values for iron. EFSA Journal 13: 4254. https:// doi.org/10.2903/j.efsa.2015.4254
European Food Safety Authority (EFSA), 2018. Guidance on the characterisation of microorganisms used as feed additives or as production organisms. EFSA Journal 16: 5206.

European Food Safety Authority (EFSA), 2020. Qualified Presumption of Safety (QPS). EFSA, Brussels, Belgium. Available at: https://www. efsa.europa.eu/en/topics/topic/qualified-presumption-safety-qps Fak, F., Ahrne, S., Linderoth, A., Molin, G., Jeppsson, B. and Westrom, B., 2008a. Age-related effects of the probiotic bacterium Lactobacillus plantarum 299v on gastrointestinal function in suckling rats. Digestive Diseases and Sciences 53: 664-671. https:// doi.org/10.1007/s10620-007-9906-1

Fak, F., Ahrne, S., Molin, G., Jeppsson, B. and Westrom, B., 2008b. Maternal consumption of Lactobacillus plantarum 299v affects gastrointestinal growth and function in the suckling rat. British Journal of Nutrition 100: 332-338. https://doi.org/10.1017/ S0007114507883036

Fink, M.P., 2002. Clinical tests of gastrointestinal permeability that rely on the urinary recovery of enterally administered probes can yield invalid results in critically ill patients. Intensive Care Medicine 28: 103-104. https://doi.org/10.1007/s00134-001-1191-4

Gareau, M.G., Jury, J., MacQueen, G., Sherman, P.M. and Perdue, M.H., 2007. Probiotic treatment of rat pups normalises corticosterone release and ameliorates colonic dysfunction induced by maternal separation. Gut 56: 1522-1528.

Gbassi, G.K., Vandamme, T., Ennahar, S. and Marchioni, E., 2009. Microencapsulation of Lactobacillus plantarum spp in an alginate matrix coated with whey proteins. International Journal of Food Microbiology 129: 103-105. https://doi.org/10.1016/j. ijfoodmicro.2008.11.012

Glenting, J., Beck, H.C., Vrang, A., Riemann, H., Ravn, P., Hansen, A.M., Antonsson, M., Ahrne, S., Israelsen, H. and Madsen, S., 2013. Anchorless surface associated glycolytic enzymes from Lactobacillus plantarum 299v bind to epithelial cells and extracellular matrix proteins. Microbiological Research 168: 245-253. https://doi. org/10.1016/j.micres.2013.01.003

Golowczyc, M., Vera, C., Santos, M., Guerrero, C., Carasi, P., Illanes, A., Gomez-Zavaglia, A. and Tymczyszyn, E., 2013. Use of whey permeate containing in situ synthesised galacto-oligosaccharides for the growth and preservation of Lactobacillus plantarum. Journal of Dairy Research 80: 374-381. https://doi.org/10.1017/ S0022029913000356

Gonzalez-Castro, A.M., Martinez, C., Salvo-Romero, E., Fortea, M., Pardo-Camacho, C., Perez-Berezo, T., Alonso-Cotoner, C., Santos, J. and Vicario, M., 2017. Mucosal pathobiology and molecular signature of epithelial barrier dysfunction in the small intestine in irritable bowel syndrome. Journal of Gastroenterology and Hepatology 32: 53-63.

Goossens, D., Jonkers, D., Russel, M., Stobberingh, E., Van den Bogaard, A. and Stockbrugger, R., 2003. The effect of Lactobacillus plantarum $299 \mathrm{v}$ on the bacterial composition and metabolic activity in faeces of healthy volunteers: a placebo-controlled study on the onset and duration of effects. Alimentary Pharmacology and Therapeutics 18: 495-505. https://doi.org/10.104.6/j.1365-2036.2003.01708.x 
Goossens, D., Jonkers, D., Russel, M., Thijs, A., Van den Bogaard, A., Stobberingh, E. and Stockbrugger, R., 2005. Survival of the probiotic, L. plantarum $299 \mathrm{v}$ and its effects on the faecal bacterial flora, with and without gastric acid inhibition. Digestive and Liver Disease 37: 44-50. https://doi.org/10.1016/j.dld.2004.07.018

Goossens, D.A., Jonkers, D.M., Russel, M.G., Stobberingh, E.E. and Stockbrugger, R.W., 2006a. The effect of a probiotic drink with Lactobacillus plantarum 299v on the bacterial composition in faeces and mucosal biopsies of rectum and ascending colon. Alimentary Pharmacology and Therapeutics 23: 255-263. https:// doi.org/10.1111/j.1365-2036.2006.0274.9.x

Goossens, D.A.M., Jonkers, D.M.A.E., Russel, M.G.V.M., Vaughan, E.E., Stobberingh, E.E. and Stockbrügger, R.W., 2006b. Bowel cleansing with subsequent intake of Lactobacillus plantarum $299 \mathrm{v}$ does not change the composition of the faecal flora. Microbial Ecology in Health and Disease 18: 139-146. https://doi. org/10.1080/08910600601040222

Gotteland, M., Cires, M.J., Carvallo, C., Vega, N., Ramirez, M.A., Morales, P., Rivas, P., Astudillo, F., Navarrete, P., Dubos, C., Figueroa, A., Troncoso, M., Ulloa, C., Mizgier, M.L., Carrasco-Pozo, C., Speisky, H., Brunser, O. and Figueroa, G., 2014. Probiotic screening and safety evaluation of Lactobacillus strains from plants, artisanal goat cheese, human stools, and breast milk. Journal of Medicinal Food 17: 487-495. https://doi.org/10.1089/jmf.2013.0030

Granfeldt, Y.E. and Bjorck, I.M., 2011. A bilberry drink with fermented oatmeal decreases postprandial insulin demand in young healthy adults. Nutrition Journal 10: 57. https://doi.org/10.1186/14752891-10-57

Gross, G., Snel, J., Boekhorst, J., Smits, M.A. and Kleerebezem, M., 2010. Biodiversity of mannose-specific adhesion in Lactobacillus plantarum revisited: strain-specific domain composition of the mannose-adhesin. Beneficial Microbes 1: 61-66. https://doi. org/10.3920/BM2008.1006

Gross, G., Van der Meulen, J., Snel, J., Van der Meer, R., Kleerebezem, M., Niewold, T.A., Hulst, M.M. and Smits, M.A., 2008a. Mannosespecific interaction of Lactobacillus plantarum with porcine jejunal epithelium. FEMS Immunology and Medical Microbiology 54: 215223. https://doi.org/10.1111/j.1574-695X.2008.00466.x

Gross, G., Wildner, J., Schonewille, A., Rademaker, J.L., Van der Meer, R. and Snel, J., 2008b. Probiotic Lactobacillus plantarum 299v does not counteract unfavorable phytohemagglutinin-induced changes in the rat intestinal microbiota. Applied and Environmental Microbiology 74: 5244-5249. https://doi.org/10.1128/AEM.00514-08

Hakansson, A., Stene, C., Mihaescu, A., Molin, G., Ahrne, S., Thorlacius, H. and Jeppsson, B., 2006. Rose hip and Lactobacillus plantarum DSM 9843 reduce ischemia/reperfusion injury in the mouse colon. Digestive Diseases and Sciences 51: 2094-2101. https:// doi.org/10.1007/s10620-006-9170-9

Hamon, E., Horvatovich, P., Izquierdo, E., Bringel, F., Marchioni, E., Aoude-Werner, D. and Ennahar, S., 2011. Comparative proteomic analysis of Lactobacillus plantarum for the identification of key proteins in bile tolerance. BMC Microbiology 11: 63. https://doi. org/10.1186/1471-2180-11-63
Hasslof, P., Hedberg, M., Twetman, S. and Stecksen-Blicks, C., 2010. Growth inhibition of oral mutans streptococci and candida by commercial probiotic lactobacilli - an in vitro study. BMC Oral Health 10: 18. https://doi.org/10.1186/1472-6831-10-18

Haukioja, A., Soderling, E. and Tenovuo, J., 2008. Acid production from sugars and sugar alcohols by probiotic lactobacilli and bifidobacteria in vitro. Caries Research 42: 449-453. https://doi. org/10.1159/000163020

Haukioja, A., Yli-Knuuttila, H., Loimaranta, V., Kari, K., Ouwehand, A.C., Meurman, J.H. and Tenovuo, J., 2006. Oral adhesion and survival of probiotic and other lactobacilli and bifidobacteria in vitro. Oral Microbiology and Immunology 21: 326-332. https:// doi.org/10.1111/j.1399-302X.2006.00299.x

Hedberg, M., Hasslöf, P., Sjöström, I., Twetman, S. and Stecksén-Blicks, C., 2008. Sugar fermentation in probiotic bacteria - an in vitro study. Oral Microbiology and Immunology 23: 482-485.

Herias, M.V., Hessle, C., Telemo, E., Midtvedt, T., Hanson, L.A. and Wold, A.E., 1999. Immunomodulatory effects of Lactobacillus plantarum colonizing the intestine of gnotobiotic rats. Clinical and Experimental Immunology 116: 283-290. https://doi.org/10.1046/ j.1365-2249.1999.00891.x

Hoffmann, A. and Daniels, R., 2018. A novel test system for the evaluation of oral mucoadhesion of fast disintegrating tablets. International Journal of Pharmaceutics 551: 141-147. https://doi. org/10.1016/j.ijpharm.2018.09.001

Holst, B., Glenting, J., Holmstrom, K., Israelsen, H., Vrang, A., Antonsson, M., Ahrne, S. and Madsen, S.M., 2019. Molecular switch controlling expression of the mannose-specific adhesin, MSA, in Lactobacillus plantarum. Applied and Environmental Microbiology 85: 02954-02918.

Hoppe, M., Onning, G. and Hulthen, L., 2017. Freeze-dried Lactobacillus plantarum 299v increases iron absorption in young females - double isotope sequential single-blind studies in menstruating women. PLoS ONE 12: e0189141. https://doi. org/10.1371/journal.pone.0189141

Hoppe, M., Onning, G., Berggren, A. and Hulthen, L., 2015. Probiotic strain Lactobacillus plantarum 299v increases iron absorption from an iron-supplemented fruit drink: a double-isotope crossover single-blind study in women of reproductive age. British Journal of Nutrition 114: 1195-1202. https://doi.org/10.1017/ S000711451500241X

Hoveyda, N., Heneghan, C., Mahtani, K.R., Perera, R., Roberts, N. and Glasziou, P., 2009. A systematic review and meta-analysis: probiotics in the treatment of irritable bowel syndrome. BMC Gastroenterology 9: 9-15.

Hulst, M., Gross, G., Liu, Y., Hoekman, A., Niewold, T., Van der Meulen, J. and Smits, M., 2015. Oral administration of Lactobacillus plantarum 299v modulates gene expression in the ileum of pigs: prediction of crosstalk between intestinal immune cells and submucosal adipocytes. Genes and Nutrition 10: 10. https://doi. org/10.1007/s12263-015-0461-7

Hutt, P., Shchepetova, J., Loivukene, K., Kullisaar, T. and Mikelsaar, M., 2006. Antagonistic activity of probiotic lactobacilli and bifidobacteria against entero- and uropathogens. Journal of Applied Microbiology 100: 1324-1332. https://doi.org/10.1111/j.1365-2672.2006.02857.x 
Isolauri, E., Sütas, Y., Kankaanpää, P., Arvilommi, H. and Salminen, S., 2001. Probiotics: effects on immunity. American Journal of Clinical Nutrition 73: 444S-450S.

Izquierdo, E., Horvatovich, P., Marchioni, E., Aoude-Werner, D., Sanz, Y. and Ennahar, S., 2009. 2-DE and MS analysis of key proteins in the adhesion of Lactobacillus plantarum, a first step toward early selection of probiotics based on bacterial biomarkers. Electrophoresis 30: 949-956. https://doi.org/10.1002/elps.200800399 Jablonska-Rys, E., Slawinska, A., Radzki, W. and Gustaw, W., 2016. Evaluation of the potential use of probiotic strain Lactobacillus plantarum 299v in lactic fermentation of button mushroom fruiting bodies. Acta Scientiarum Polonorum: Technologia Alimentaria 15: 399-407. https://doi.org/10.17306/J.AFS.2016.4.38

Jacobsen, C.N., Rosenfeldt Nielsen, V., Hayford, A.E., Moller, P.L., Michaelsen, K.F., Paerregaard, A., Sandstrom, B., Tvede, M. and Jakobsen, M., 1999. Screening of probiotic activities of forty-seven strains of Lactobacillus spp. by in vitro techniques and evaluation of the colonization ability of five selected strains in humans. Applied and Environmental Microbiology 65: 4949-4956. https://doi. org/10.1128/AEM.65.11.4949-4956.1999

Jakubczyk, A., Karas, M., Baraniak, B. and Pietrzak, M., 2013. The impact of fermentation and in vitro digestion on formation angiotensin converting enzyme (ACE) inhibitory peptides from pea proteins. Food Chemistry 141: 3774-3780. https://doi.org/10.1016/j. foodchem.2013.06.095

Jensen, H., Dromtorp, S.M., Axelsson, L. and Grimmer, S., 2015. Immunomodulation of monocytes by probiotic and selected lactic acid bacteria. Probiotics and Antimicrobial Proteins 7: 14-23. https:// doi.org/10.1007/s12602-014-9174-2

Jensen, H., Grimmer, S., Naterstad, K. and Axelsson, L., 2012. In vitro testing of commercial and potential probiotic lactic acid bacteria. International Journal of Food Microbiology 153: 216-222. https:// doi.org/10.1016/j.ijfoodmicro.2011.11.020

Jiang, X., Xu, H.J., Cui, Y.G. and Zhang, Y.G., 2020. Effects of supplementation with Lactobacillus plantarum 299v on the performance, blood metabolites, rumen fermentation and bacterial communities of preweaning calves. Livestock Science 239: 104120.

Johansson, M.E., Gustafsson, J.K., Holmen-Larsson, J., Jabbar, K.S., Xia, L., Xu, H., Ghishan, F.K., Carvalho, F.A., Gewirtz, A.T., Sjovall, H. and Hansson, G.C., 2014. Bacteria penetrate the normally impenetrable inner colon mucus layer in both murine colitis models and patients with ulcerative colitis. Gut 63: 281-291. https://doi. org/10.1136/gutjnl-2012-303207

Johansson, M.L., Molin, G., Jeppsson, B., Nobaek, S., Ahrné, S. and Bengmark, S., 1993. Administration of different Lactobacillus strains in fermented oatmeal soup: in vivo colonization of human intestinal mucosa and effect on the indigenous flora. Applied and Environmental Microbiology 59: 15-20.

Johansson, M.-L., Molin, G., Pettersson, B., Uhlén, M. and Ahrné, S., 1995a. Characterization and species recognition of Lactobacillus plantarum strains by restriction fragment length polymorphism (RFLP) of the 16S rRNA gene. Journal of Applied Bacteriology 79: 536-541. https://doi.org/10.1111/j.1365-2672.1995.tb03174.x
Johansson, M.L., Nobaek, S., Berggren, A., Nyman, M., Bjorck, I., Ahrne, S., Jeppsson, B. and Molin, G., 1998. Survival of Lactobacillus plantarum DSM 9843 (299v), and effect on the short-chain fatty acid content of faeces after ingestion of a rose-hip drink with fermented oats. International Journal of Food Microbiology 42: 29-38. https:// doi.org/10.1016/s0168-1605(98)00055-5

Johansson, M.-L., Quednau, M., Ahrné, S. and Molin, G., 1995b. Classification of Lactobacillus plantarum by restriction endonuclease analysis of total chromosomal DNA using conventional agarose gel electrophoresis. International Journal of Systematic and Evolutionary Microbiology 45: 670-675. https:// doi.org/10.1099/00207713-45-4-670

Johansson, M.L., Quednau, M., Molin, G. and Ahrne, S., 1995c. Randomly amplified polymorphic DNA (RAPD) for rapid typing of Lactobacillus plantarum strains. Letters in Applied Microbiology 21: 155-159. https://doi.org/10.1111/j.1472-765x.1995.tb01030.x Jones, C., Badger, S.A., Regan, M., Clements, B.W., Diamond, T., Parks, R.W. and Taylor, M.A., 2013. Modulation of gut barrier function in patients with obstructive jaundice using probiotic LP299v. European Journal of Gastroenterology and Hepatology 25: 1424-1430. https:// doi.org/10.1097/MEG.0b013e328363e26e

Jonsson, S., Clausen, E. and Raa, J., 1983. Amino acid degradation by a Lactobacillus plantarum strain from fish. Systematic and Applied Microbiology 4: 148-154. https://doi.org/10.1016/S07232020(83)80043-5

Joossens, M., Huys, G., Cnockaert, M., De Preter, V., Verbeke, K., Rutgeerts, P., Vandamme, P. and Vermeire, S., 2011. Dysbiosis of the faecal microbiota in patients with Crohn's disease and their unaffected relatives. Gut 60: 631-637. https://doi.org/10.1136/ gut.2010.223263

Karlsson, C., Ahrne, S., Molin, G., Berggren, A., Palmquist, I., Fredrikson, G.N. and Jeppsson, B., 2010. Probiotic therapy to men with incipient arteriosclerosis initiates increased bacterial diversity in colon: a randomized controlled trial. Atherosclerosis 208: 228-233. https://doi.org/10.1016/j.atherosclerosis.2009.06.019

Kasravi, F.B., Adawi, D., Molin, G., Bengmark, S. and Jeppsson, B., 1997. Effect of oral supplementation of lactobacilli on bacterial translocation in acute liver injury induced by D-galactosamine. Journal of Hepatology 26: 417-424.

Keller, M.K. and Twetman, S., 2012. Acid production in dental plaque after exposure to probiotic bacteria. BMC Oral Health 12: 44. https:// doi.org/10.1186/1472-6831-12-44

Khanian, M., Karimi-Torshizi, M.-A. and Allameh, A., 2019. Alleviation of aflatoxin-related oxidative damage to liver and improvement of growth performance in broiler chickens consumed Lactobacillus plantarum 299v for entire growth period. Toxicon 158: 57-62. https://doi.org/10.1016/j.toxicon.2018.11.431

King, T.S., Elia, M. and Hunter, J.O., 1998. Abnormal colonic fermentation in irritable bowel syndrome. The Lancet 352: 11871189. https://doi.org/10.1016/s0140-6736(98)02146-1

Kingamkono, R., Sjogren, E. and Svanberg, U., 1999. Enteropathogenic bacteria in faecal swabs of young children fed on lactic acidfermented cereal gruels. Epidemiology and Infection 122: 23-32. https://doi.org/10.1017/s0950268898001800 
Klarin, B., Johansson, M.L., Molin, G., Larsson, A. and Jeppsson, B., 2005. Adhesion of the probiotic bacterium Lactobacillus plantarum $299 \mathrm{v}$ onto the gut mucosa in critically ill patients: a randomised open trial. Critical Care 9: R285-293. https://doi.org/10.1186/cc3522

Klarin, B., Larsson, A., Molin, G. and Jeppsson, B., 2019. Susceptibility to antibiotics in isolates of Lactobacillus plantarum RAPD-type Lp299v, harvested from antibiotic treated, critically ill patients after administration of probiotics. MicrobiologyOpen 8: e00642-e00642. https://doi.org/10.1002/mbo3.642

Klarin, B., Wullt, M., Palmquist, I., Molin, G., Larsson, A. and Jeppsson, B., 2008. Lactobacillus plantarum 299v reduces colonisation of Clostridium difficile in critically ill patients treated with antibiotics. Acta Anaesthesiologica Scandinavica 52: 1096-1102. https://doi. org/10.1111/j.1399-6576.2008.01748.x

Korcok, D.J., Trsic-Milanovic, N.A., Ivanovic, N.D. and Dordevic, B.I., 2018. Development of probiotic formulation for the treatment of iron deficiency anemia. Chemical \& Pharmaceutical Bulletin 66: 347-352. https://doi.org/10.1248/cpb.c17-00634

Kortman, G.A., Boleij, A., Swinkels, D.W. and Tjalsma, H., 2012. Iron availability increases the pathogenic potential of Salmonella typhimurium and other enteric pathogens at the intestinal epithelial interface. PLoS ONE 7: e29968. https://doi.org/10.1371/journal. pone.0029968

Krag, A., Israelsen, H., Von Ryberg, B., Andersen, K.K. and Bendtsen, F., 2012. Safety and efficacy of Profermin ${ }^{\oplus}$ to induce remission in ulcerative colitis. World Journal of Gastroenterology 18: 1773-1780. https://doi.org/10.3748/wjg.v18.i15.1773

Krag, A., Munkholm, P., Israelsen, H., Von Ryberg, B., Andersen, K.K. and Bendtsen, F., 2013. Profermin is efficacious in patients with active ulcerative colitis - a randomized controlled trial. Inflammatory Bowel Diseases 19: 2584-2592. https://doi. org/10.1097/01.MIB.0000437046.26036.db

Kujawa-Szewieczek, A., Adamczak, M., Kwiecien, K., Dudzicz, S., Gazda, M. and Wiecek, A., 2015. The effect of Lactobacillus plantarum 299v on the incidence of Clostridium difficile infection in high risk patients treated with antibiotics. Nutrients 7: 1017910188. https://doi.org/10.3390/nu7125526

La Fata, G., Weber, P. and Mohajeri, M.H., 2018. Probiotics and the gut immune system: indirect regulation. Probiotics and Antimicrobial Proteins 10: 11-21.

Lacy, B.E., Mearin, F., Chang, L., Chey, W.D., Lembo, A.J., Simren, M. and Spiller, R., 2016. Bowel disorders. Gastroenterology 150: 1393-1407. https://doi.org/10.1053/j.gastro.2016.02.031

Ladas, E.J., Bhatia, M., Chen, L., Sandler, E., Petrovic, A., Berman, D.M., Hamblin, F., Gates, M., Hawks, R., Sung, L. and Nieder, M., 2016. The safety and feasibility of probiotics in children and adolescents undergoing hematopoietic cell transplantation. Bone Marrow Transplantation 51: 262-266. https://doi.org/10.1038/bmt.2015.275

Lam, V., Su, J., Koprowski, S., Hsu, A., Tweddell, J.S., Rafiee, P., Gross, G.J., Salzman, N.H. and Baker, J.E., 2012. Intestinal microbiota determine severity of myocardial infarction in rats. FASEB Journal 26: 1727-1735. https://doi.org/10.1096/fj.11-197921

Liljeberg, H. and Björck, I., 1998. Delayed gastric emptying rate may explain improved glycaemia in healthy subjects to a starchy meal with added vinegar. European Journal of Clinical Nutrition 52: 368-371.
Liu, Q., Nobaek, S., Adawi, D., Mao, Y., Wang, M., Molin, G., Ekelund, M. and Jeppsson, B., 2001. Administration of Lactobacillus plantarum 299v reduces side-effects of external radiation on colon anastomotic healing in an experimental model. Colorectal Disease 3: 245-252. https://doi.org/10.1046/j.1463-1318.2001.00244.x

Lonnermark, E., Friman, V., Lappas, G., Sandberg, T., Berggren, A. and Adlerberth, I., 2010. Intake of Lactobacillus plantarum reduces certain gastrointestinal symptoms during treatment with antibiotics. Journal of Clinical Gastroenterology 44: 106-112. https:// doi.org/10.1097/MCG.0b013e3181b2683f

Lonnermark, E., Lappas, G., Friman, V., Wold, A.E., Backhaus, E. and Adlerberth, I., 2015. Effects of probiotic intake and gender on nontyphoid Salmonella infection. Journal of Clinical Gastroenterology 49: 116-123. https://doi.org/10.1097/ MCG.0000000000000120

Low, D., Nguyen, D.D. and Mizoguchi, E., 2013. Animal models of ulcerative colitis and their application in drug research. Drug Design, Development and Therapy 7: 1341-1357. https://doi.org/10.2147/ DDDT.S4.0107

Low, M.S., Speedy, J., Styles, C.E., De-Regil, L.M. and Pasricha, S.R., 2016. Daily iron supplementation for improving anaemia, iron status and health in menstruating women. Cochrane Database of Systematic Reviews 4: CD009747. https://doi.org/10.1002/14651858. CD009747.pub2

Mack, D.R., Ahrne, S., Hyde, L., Wei, S. and Hollingsworth, M.A., 2003. Extracellular MUC3 mucin secretion follows adherence of Lactobacillus strains to intestinal epithelial cells in vitro. Gut 52: 827-833. https://doi.org/10.1136/gut.52.6.827

Mack, D.R., Michail, S., Wei, S., McDougall, L. and Hollingsworth, M.A., 1999. Probiotics inhibit enteropathogenic E. coli adherence in vitro by inducing intestinal mucin gene expression. American Journal of Physiology 276: G941-950. https://doi.org/10.1152/ ajpgi.1999.276.4.G941

Malago, J.J., Nemeth, E., Koninkx, J.F., Tooten, P.C., Fajdiga, S. and Van Dijk, J.E., 2010. Microbial products from probiotic bacteria inhibit Salmonella enteritidis 857-induced IL-8 synthesis in Caco-2 cells. Folia Microbiologica 55: 401-408. https://doi.org/10.1007/ s12223-010-0068-8

Malik, M., Suboc, T.M., Tyagi, S., Salzman, N., Wang, J., Ying, R., Tanner, M.J., Kakarla, M., Baker, J.E. and Widlansky, M.E., 2018. Lactobacillus plantarum 299v supplementation improves vascular endothelial function and reduces inflammatory biomarkers in men with stable coronary artery disease. Circulation Research 123: 1091-1102. https://doi.org/10.1161/CIRCRESAHA.118.313565

Mangell, P., Lennernas, P., Wang, M., Olsson, C., Ahrne, S., Molin, G., Thorlacius, H. and Jeppsson, B., 2006. Adhesive capability of Lactobacillus plantarum $299 \mathrm{v}$ is important for preventing bacterial translocation in endotoxemic rats. APMIS 114: 611-618. https:// doi.org/10.1111/j.1600-0463.2006.apm_369.x

Mangell, P., Nejdfors, P., Wang, M., Ahrne, S., Westrom, B., Thorlacius, H. and Jeppsson, B., 2002. Lactobacillus plantarum 299v inhibits Escherichia coli-induced intestinal permeability. Digestive Diseases and Sciences 47: 511-516. https://doi.org/10.1023/a:1017947531536 
Mangell, P., Thorlacius, H., Syk, I., Ahrne, S., Molin, G., Olsson, C. and Jeppsson, B., 2012. Lactobacillus plantarum 299v does not reduce enteric bacteria or bacterial translocation in patients undergoing colon resection. Digestive Diseases and Sciences 57: 1915-1924. https://doi.org/10.1007/s10620-012-2102-y

Mangiante, G., Canepari, P., Colucci, G., Marinello, P., Signoretto, C., Nicoli, N. and Bengmark, S., 1999. A probiotic as an antagonist of bacterial translocation in experimental pancreatitis. Chirurgia Italiana 51: 221-226.

Mangiante, G., Colucci, G., Canepari, P., Bassi, C., Nicoli, N., Casaril, A., Marinello, P., Signoretto, C. and Bengmark, S., 2001a. Lactobacillus plantarum reduces infection of pancreatic necrosis in experimental acute pancreatitis. Digestive Surgery 18: 47-50. https://doi.org/10.1159/000050096

Mangiante, G., Colucci, G., Gottin, L., Casaril, A., Ciola, M., Facci, E. and Nicoli, N., 2001b. Effect of probiotic administration on colic anastomosis healing. Chirurgia Italiana 53: 39-44.

Manirarora, J.N., Kosiewicz, M.M. and Alard, P., 2020. Feeding lactobacilli impacts lupus progression in (NZBxNZW)F1 lupusprone mice by enhancing immunoregulation. Autoimmunity 53: 323-332.

Mao, Y., Nobaek, S., Kasravi, B., Adawi, D., Stenram, U., Molin, G. and Jeppsson, B., 1996a. The effects of Lactobacillus strains and oat fiber on methotrexate-induced enterocolitis in rats. Gastroenterology 111: 334-344. https://doi.org/10.1053/gast.1996.v111.pm8690198

Mao, Y., Yu, J.L., Ljungh, Å., Molin, G. and Jeppsson, B., 1996b. Intestinal immune response to oral administration of Lactobacillus reuteri R2LC, Lactobacillus plantarum DSM 9843, pectin and oatbase on methotrexateinduced enterocolitis in rats. Microbial Ecology in Health and Disease 9: 261-269. https://doi.org/10.3402/ mehd.v9i6.8390

Marco, M.L., De Vries, M.C., Wels, M., Molenaar, D., Mangell, P., Ahrne, S., De Vos, W.M., Vaughan, E.E. and Kleerebezem, M., 2010. Convergence in probiotic Lactobacillus gut-adaptive responses in humans and mice. ISME Journal 4: 1481-1484. https://doi. org/10.1038/ismej.2010.61

Marklinder, I. and Johansson, L., 1995. Sour dough fermentation of barley flours with varied content of mixed-linked (1->3), (1->4) beta-D-glucans Food Microbiology 12: 363-371.

Marklinder, I. and Lönner, C., 1994. Fermented oatmeal soup influence of additives on the properties of a nutrient solution for enteral feeding. Food Microbiology 11: 505-513.

Marklinder, I., Larsson, M., Fredlund, K. and Sandberg, A.-S., 1995. Degradation of phytate by using varied sources of phytases in an oat-based nutrient solution fermented by Lactobacillus plantarum strain 299v. Food Microbiology 12: 487-495.

Marshall, J.C., Christou, N.V. and Meakins, J.L., 1993. The gastrointestinal tract. The 'undrained abscess' of multiple organ failure. Annals of Surgery 218: 111-119. https://doi. org/10.1097/00000658-199308000-00001

McCarney, R., Warner, J., Iliffe, S., Van Haselen, R., Griffin, M. and Fisher, P., 2007. The Hawthorne effect: a randomised, controlled trial. BMC Medical Research Methodology 7: 1471-2288.
McCracken, V.J., Chun, T., Baldeon, M.E., Ahrne, S., Molin, G., Mackie, R.I. and Gaskins, H.R., 2002. TNF-alpha sensitizes HT-29 colonic epithelial cells to intestinal lactobacilli. Experimental Biology and Medicine 227: 665-670.

McFarland, L.V., Evans, C.T. and Goldstein, E.J.C., 2018. Strainspecificity and disease-specificity of probiotic efficacy: a systematic review and meta-analysis. Frontiers in Medicine 5: 124. https://doi. org/10.3389/fmed.2018.00124

McNaught, C.E., Woodcock, N.P., Anderson, A.D. and MacFie, J., 2005. A prospective randomised trial of probiotics in critically ill patients. Clinical Nutrition 24: 211-219. https://doi.org/10.1016/j. clnu.2004.08.008

McNaught, C.E., Woodcock, N.P., MacFie, J. and Mitchell, C.J., 2002. A prospective randomised study of the probiotic Lactobacillus plantarum $299 \mathrm{~V}$ on indices of gut barrier function in elective surgical patients. Gut 51: 827-831. https://doi.org/10.1136/ gut.51.6.827

Mearin, F., Lacy, B.E., Chang, L., Chey, W.D., Lembo, A.J., Simren, M. and Spiller, R., 2016. Bowel disorders. Gastroenterology 18: 222-225.

Melgar-Lalanne, G., Rivera-Espinoza, Y., Reyes Mendez, A.I. and Hernandez-Sanchez, H., 2013. In vitro evaluation of the probiotic potential of halotolerant lactobacilli isolated from a ripened tropical Mexican cheese. Probiotics and Antimicrobial Proteins 5: 239-251. https://doi.org/10.1007/s12602-013-9144-0

Michail, S. and Abernathy, F., 2002. Lactobacillus plantarum reduces the in vitro secretory response of intestinal epithelial cells to enteropathogenic Escherichia coli infection. Journal of Pediatric Gastroenterology and Nutrition 35: 350-355. https://doi. org/10.1097/00005176-200209000-00021

Mirkovic, M., Seratlic, S., Kilcawley, K., Mannion, D., Mirkovic, N. and Radulovic, Z., 2018. The sensory quality and volatile profile of dark chocolate enriched with encapsulated probiotic Lactobacillus plantarum bacteria. Sensors 18: 2570. https://doi.org/10.3390/ s18082570

Mitselou, A., Grammeniatis, V., Varouktsi, A., Papadatos, S.S., Katsanos, K. and Galani, V., 2020. Proinflammatory cytokines in irritable bowel syndrome: a comparison with inflammatory bowel disease. Intestinal Research 18: 115-120.

Modi, N. and Wilcox, M.H., 2001. Evidence for antibiotic induced Clostridium perfringens diarrhoea. Journal of Clinical Pathology 54: 748-751. https://doi.org/10.1136/jcp.54.10.748

Molenaar, D., Bringel, F., Schuren, F.H., De Vos, W.M., Siezen, R.J. and Kleerebezem, M., 2005. Exploring Lactobacillus plantarum genome diversity by using microarrays. Journal of Bacteriology 187: 6119-6127. https://doi.org/10.1128/JB.187.17.6119-6127.2005

Molin, G., 1994. Lactobacillus strains for fermented oatmeal soup in ProViva. Presses Universitaire de Caen, Caen, France, pp. 213-223.

Molin, G., 2001. Probiotics in foods not containing milk or milk constituents, with special reference to Lactobacillus plantarum 299v. American Journal of Clinical Nutrition 73: 380S-385S. https:// doi.org/10.1093/ajcn/73.2.380s

Molin, G., Jeppsson, B., Johansson, M.L., Ahrne, S., Nobaek, S., Stahl, M. and Bengmark, S., 1993. Numerical taxonomy of Lactobacillus spp. associated with healthy and diseased mucosa of the human intestines. Journal of Applied Bacteriology 74: 314-323. https:// doi.org/10.1111/j.1365-2672.1993.tb03031.x 
Moretti, D., Goede, J.S., Zeder, C., Jiskra, M., Chatzinakou, V., Tjalsma, H., Melse-Boonstra, A., Brittenham, G., Swinkels, D.W. and Zimmermann, M.B., 2015. Oral iron supplements increase hepcidin and decrease iron absorption from daily or twice-daily doses in iron-depleted young women. Blood 126: 1981-1989. https:// doi.org/10.1182/blood-2015-05-642223

Naruszewicz, M., Johansson, M.L., Zapolska-Downar, D. and Bukowska, H., 2002. Effect of Lactobacillus plantarum 299v on cardiovascular disease risk factors in smokers. American Journal of Clinical Nutrition 76: 1249-1255. https://doi.org/10.1093/ ajcn/76.6.1249

Nguyen, B.T., Bujna, E., Fekete, N., Tran, A.T.M., Rezessy-Szabo, J.M., Prasad, R. and Nguyen, Q.D., 2019. Probiotic beverage from pineapple juice fermented with Lactobacillus and Bifidobacterium strains. Fronters in Nutrition 6: 54. https://doi.org/10.3389/ fnut.2019.00054

Niedzielin, K., Kordecki, H. and Birkenfeld, B., 2001. A controlled, double-blind, randomized study on the efficacy of Lactobacillus plantarum $299 \mathrm{~V}$ in patients with irritable bowel syndrome. European Journal of Gastroenterology and Hepatology 13: 11431147. https://doi.org/10.1097/00042737-200110000-00004

Nigatu, A., Ahrné, S. and Molin, G., 2001. Randomly amplified polymorphic DNA (RAPD) profiles for the distinction of Lactobacillus species. Antonie Van Leeuwenhoek 79: 1-6. https:// doi.org/10.1023/a:1010290403124

Nilsson, A., Johansson-Boll, E., Sandberg, J. and Bjorck, I., 2016. Gut microbiota mediated benefits of barley kernel products on metabolism, gut hormones, and inflammatory markers as affected by co-ingestion of commercially available probiotics: a randomized controlled study in healthy subjects. Clinical Nutrition ESPEN 15: 49-56. https://doi.org/10.1016/j.clnesp.2016.06.006

Nobaek, S., Johansson, M.L., Molin, G., Ahrne, S. and Jeppsson, B., 2000. Alteration of intestinal microflora is associated with reduction in abdominal bloating and pain in patients with irritable bowel syndrome. American Journal of Gastroenterology 95: 1231-1238. https://doi.org/10.1111/j.1572-0241.2000.02015.x

Olek, A., Woynarowski, M., Ahren, I.L., Kierkus, J., Socha, P., Larsson, N. and Onning, G., 2017. Efficacy and safety of Lactobacillus plantarum DSM 9843 (LP299V) in the prevention of antibioticassociated gastrointestinal symptoms in children-randomized, double-blind, placebo-controlled study. Journal of Pediatrics 186: 82-86.

Onning, G., Berggren, A., Drevelius, M., Jeppsson, B., Lindberg, A.M. and Johansson Hagslatt, M.L., 2003. Influence of a drink containing different antioxidants and Lactobacillus plantarum 299v on plasma total antioxidant capacity, selenium status and faecal microbial flora. International Journal of Food Sciences and Nutrition 54: 281-289. https://doi.org/10.1080/0963748031000091964.

Ortiz-Lucas, M., Tobias, A., Saz, P. and Sebastian, J.J., 2013. Effect of probiotic species on irritable bowel syndrome symptoms: a bring up to date meta-analysis. Revista Española de Enfermedades Digestivas 105: 19-36.
Osman, N., Adawi, D., Ahrne, S., Jeppsson, B. and Molin, G., 2004. Modulation of the effect of dextran sulfate sodium-induced acute colitis by the administration of different probiotic strains of Lactobacillus and Bifidobacterium. Digestive Diseases and Sciences 49: 320-327.

Oudemans-Van Straaten, H.M., Van der Voort, P.J., Hoek, F.J., Bosman, R.J., Van der Spoel, J.I. and Zandstra, D.F., 2002. Pitfalls in gastrointestinal permeability measurement in ICU patients with multiple organ failure using differential sugar absorption. Intensive Care Medicine 28: 130-138. https://doi.org/10.1007/s00134-0011140-2

Oudhuis, G.J., Bergmans, D.C., Dormans, T., Zwaveling, J.H., Kessels, A., Prins, M.H., Stobberingh, E.E. and Verbon, A., 2011. Probiotics versus antibiotic decontamination of the digestive tract: infection and mortality. Intensive Care Medicine 37: 110-117. https://doi. org/10.1007/s00134-010-2002-6

Palleja, A., Mikkelsen, K.H., Forslund, S.K., Kashani, A., Allin, K.H., Nielsen, T., Hansen, T.H., Liang, S., Feng, Q., Zhang, C., Pyl, P.T., Coelho, L.P., Yang, H., Wang, J., Typas, A., Nielsen, M.F., Nielsen, H.B., Bork, P., Vilsboll, T., Hansen, T., Knop, F.K., Arumugam, M. and Pedersen, O., 2018. Recovery of gut microbiota of healthy adults following antibiotic exposure. Nature Microbiology 3: 1255-1265. https://doi.org/10.1038/s41564-018-0257-9

Pandey, S., Senthilguru, K., Uvanesh, K., Sagiri, S.S., Behera, B., Babu, N., Bhattacharyya, M.K., Pal, K. and Banerjee, I., 2016. Natural gum modified emulsion gel as single carrier for the oral delivery of probiotic-drug combination. International Journal of Biological Macromolecules 92: 504-514. https://doi.org/10.1016/j. ijbiomac.2016.07.053

Pathmakanthan, S., Li, C.K., Cowie, J. and Hawkey, C.J., 2004. Lactobacillus plantarum 299: beneficial in vitro immunomodulation in cells extracted from inflamed human colon. Journal of Gastroenterology and Hepatology 19: 166-173. https://doi. org/10.1111/j.1440-1746.2004.03181.x

Peoples, J.D., Cheung, S., Nesin, M., Lin, H., Tatad, A.M., Hoang, D., Perlman, J.M. and Cunningham-Rundles, S., 2009. Neonatal cord blood subsets and cytokine response to bacterial antigens. American Journal of Perinatology 26: 647-657. https://doi. org/10.1055/s-0029-1220788

Peterson, C.T., Sharma, V., Elmén, L. and Peterson, S.N., 2015. Immune homeostasis, dysbiosis and therapeutic modulation of the gut microbiota. Clinical and Experimental Immunology 179: 363-377.

Pretzer, G., Snel, J., Molenaar, D., Wiersma, A., Bron, P.A., Lambert, J., De Vos, W.M., Van der Meer, R., Smits, M.A. and Kleerebezem, M., 2005. Biodiversity-based identification and functional characterization of the mannose-specific adhesin of Lactobacillus plantarum. Journal of Bacteriology 187: 6128-6136. https://doi. org/10.1128/JB.187.17.6128-6136.2005

Quigley, E.M., 2008. Probiotics in functional gastrointestinal disorders: what are the facts? Current Opinion in Pharmacology 8: 704-708. https://doi.org/10.1016/j.coph.2008.08.007

Rask, C., Adlerberth, I., Berggren, A., Ahren, I.L. and Wold, A.E., 2013. Differential effect on cell-mediated immunity in human volunteers after intake of different lactobacilli. Clinical and Experimental Immunology 172: 321-332. https://doi.org/10.1111/cei.12055 
Reid, G. and Burton, J., 2002. Use of Lactobacillus to prevent infection by pathogenic bacteria. Microbes and Infection 4: 319-324. https:// doi.org/10.1016/s1286-4579(02)01544-7

Rodriguez, U., Gonzalez, K. and Shene, C., 2020. Replacement of fish meal by solid state fermented lupin (Lupinus albus) meal with Latobacillus plantarum 299v: effect on growth and immune status of juvenile Atlantic salmon (Salmo salar). Annals of Animal Science 20: 991-1009. https://doi.org/10.2478/aoas-2020-0010

Rosen, G.M., Morrissette, S., Larson, A., Stading, P., Griffin, K.H. and Barnes, T.L., 2019. Use of a probiotic to enhance iron absorption in a randomized trial of pediatric patients presenting with iron deficiency. Journal of Pediatrics 4: 31743-31748.

Rudzki, L., Ostrowska, L., Pawlak, D., Małus, A., Pawlak, K., Waszkiewicz, N. and Szulc, A., 2019. Probiotic Lactobacillus plantarum 299v decreases kynurenine concentration and improves cognitive functions in patients with major depression: a double-blind, randomized, placebo controlled study. Psychoneuroendocrinology 100: 213-222. https://doi.org/10.1016/j.psyneuen.2018.10.010

Saad, N., Urdaci, M., Vignoles, C., Chaignepain, S., Tallon, R., Schmitter, J.M. and Bressollier, P., 2009. Lactobacillus plantarum 299v surface-bound GAPDH: a new insight into enzyme cell walls location. Journal of Microbiology and Biotechnology 19: 1635-1643. https://doi.org/10.4014/jmb.0902.0102

Saffouri, G.B., Shields-Cutler, R.R., Chen, J., Yang, Y., Lekatz, H.R., Hale, V.L., Cho, J.M., Battaglioli, E.J., Bhattarai, Y., Thompson, K.J., Kalari, K.K., Behera, G., Berry, J.C., Peters, S.A., Patel, R., Schuetz, A.N., Faith, J.J., Camilleri, M., Sonnenburg, J.L., Farrugia, G., Swann, J.R., Grover, M., Knights, D. and Kashyap, P.C., 2019. Small intestinal microbial dysbiosis underlies symptoms associated with functional gastrointestinal disorders. Nature Communications 10: 2012. https:// doi.org/10.1038/s41467-019-09964-7

Salim, S.Y. and Soderholm, J.D., 2011. Importance of disrupted intestinal barrier in inflammatory bowel diseases. Inflammatory Bowel Diseases 17: 362-381. https://doi.org/10.1002/ibd.21403

Salovaara, S., Larsson Alminger, M., Eklund-Jonsson, C., Andlid, T. and Sandberg, A.S., 2003. Prolonged transit time through the stomach and small intestine improves iron dialyzability and uptake in vitro. Journal of Agricultural and Food Chemistry 51: 5131-5136.

Salovaara, S., Sandberg, A.S. and Andlid, T., 2002. Organic acids influence iron uptake in the human epithelial cell line Caco-2. Journal of Agricultural and Food Chemistry 50: 6233-6238.

Sandberg, A.S., Onning, G., Engstrom, N. and Scheers, N., 2018. Iron supplements containing Lactobacillus plantarum 299v increase ferric iron and up-regulate the ferric reductase DCYTB in human Caco-2/HT29 MTX co-cultures. Nutrients 10: 1949. https://doi. org/10.3390/nu10121949

Santaolalla, R., Fukata, M. and Abreu, M.T., 2011. Innate immunity in the small intestine. Current Opinion in Gastroenterology 27: 125-131.

Saulnier, D.M., Gibson, G.R. and Kolida, S., 2008. In vitro effects of selected synbiotics on the human faecal microbiota composition. FEMS Microbiology Ecology 66: 516-527.

Scheers, N., Rossander-Hulthen, L., Torsdottir, I. and Sandberg, A.S., 2016. Increased iron bioavailability from lactic-fermented vegetables is likely an effect of promoting the formation of ferric iron ( $\mathrm{Fe}(3+))$. European Journal of Nutrition 55: 373-382.
Schultz, M., Veltkamp, C., Dieleman, L.A., Grenther, W.B., Wyrick, P.B., Tonkonogy, S.L. and Sartor, R.B., 2002. Lactobacillus plantarum $299 \mathrm{~V}$ in the treatment and prevention of spontaneous colitis in interleukin-10-deficient mice. Inflammatory Bowel Diseases 8: 71-80. https://doi.org/10.1097/00054725-200203000-00001

Sen, S., Mullan, M.M., Parker, T.J., Woolner, J.T., Tarry, S.A. and Hunter, J.O., 2002. Effect of Lactobacillus plantarum 299v on colonic fermentation and symptoms of irritable bowel syndrome. Digestive Diseases and Sciences 47: 2615-2620. https://doi. org/10.1023/a:1020597001460

Serra, S., Simeis, D., Castagna and Valentino, 2020. The fatty-acid hydratase activity of the most common probiotic microorganisms. Catalysts 10: 154. https://doi.org/10.3390/catal10020154

Shah, E. and Pimentel, M., 2014. Placebo effect in clinical trial design for irritable bowel syndrome. Journal of Neurogastroenterology and Motility 20: 163-170. https://doi.org/10.5056/jnm.2014.20.2.163

Sica, G.S. and Biancone, L., 2013. Surgery for inflammatory bowel disease in the era of laparoscopy. World Journal of Gastroenterology 19: 2445-2448. https://doi.org/10.3748/wjg.v19.i16.2445

Simren, M., Barbara, G., Flint, H.J., Spiegel, B.M., Spiller, R.C., Vanner, S., Verdu, E.F., Whorwell, P.J. and Zoetendal, E.G. 2013. Intestinal microbiota in functional bowel disorders: a Rome foundation report. Gut 62: 159-176. https://doi.org/10.1136/gutjnl-2012-302167

Skrypnik, K., Bogdanski, P., Schmidt, M. and Suliburska, J., 2019. The effect of multispecies probiotic supplementation on iron status in rats. Biological Trace Element Research 192: 234-243. https://doi. org/10.1007/s12011-019-1658-1

Skrypnik, K., Bogdański, P., Sobieska, M. and Suliburska, J., 2020. Hepcidin and erythroferrone correlate with hepatic iron transporters in rats supplemented with multispecies probiotics. Molecules 25: 1674.

Smits, W.K., Lyras, D., Lacy, D.B., Wilcox, M.H. and Kuijper, E.J., 2016. Clostridium difficile infection. Nature Reviews Disease Primers 2: 16020. https://doi.org/10.1038/nrdp.2016.20

Sniffen, J.C., McFarland, L.V., Evans, C.T. and Goldstein, E.J.C., 2018. Choosing an appropriate probiotic product for your patient: an evidence-based practical guide. PLoS ONE 13: e0209205. https:// doi.org/10.1371/journal.pone.0209205

Soderling, E.M., Marttinen, A.M. and Haukioja, A.L., 2011. Probiotic lactobacilli interfere with Streptococcus mutans biofilm formation in vitro. Current Microbiology 62: 618-622. https://doi.org/10.1007/ s00284-010-9752-9

Sreekumar, R., Al-Attabi, Z., Deeth, H.C. and Turner, M.S., 2009. Volatile sulfur compounds produced by probiotic bacteria in the presence of cysteine or methionine. Letters in Applied Microbiology 48: 777-782. https://doi.org/10.1111/j.1472-765X.2009.02610.x

Stange, E.F. and Schroeder, B.O., 2019. Microbiota and mucosal defense in IBD: an update. Expert Review of Gastroenterology and Hepatology 13: 963-976. https://doi.org/10.1080/17474124. 2019.1671822

Stevenson, C., Blaauw, R., Fredericks, E., Visser, J. and Roux, S., 2014. Randomized clinical trial: effect of Lactobacillus plantarum 299v on symptoms of irritable bowel syndrome. Nutrition 30: 1151-1157. https://doi.org/10.1016/j.nut.2014.02.010 
Stjernquist-Desatnik, A., Warfving, H. and Johansson, M.L., 2000. Persistence of Lactobacillus plantarum DSM 9843 on human tonsillar surface after oral administration in fermented oatmeal gruel. A pilot study. Acta Oto-Laryngologica. Supplementum 543: 215-219. https://doi.org/10.1080/000164800454422

Stones, D.H. and Krachler, A.-M., 2015. Fatal attraction: how bacterial adhesins affect host signaling and what we can learn from them. International Journal of Molecular Sciences 16: 2626-2640. https:// doi.org/10.3390/ijms16022626

Swieca, M., Gawlik-Dziki, U., Jakubczyk, A., Bochnak, J., Sikora, M. and Suliburska, J., 2019. Nutritional quality of fresh and stored legumes sprouts - effect of Lactobacillus plantarum 299v enrichment. Food Chemistry 288: 325-332. https://doi.org/10.1016/j. foodchem.2019.02.135

Świeca, M., Herok, A., Piwowarczyk, K., Sikora, M., Ostanek, P., GawlikDziki, U., Kapusta, I. and Czyż, J., 2020. Potentially bioaccessible phenolics from mung bean and adzuki bean sprouts enriched with probiotic-antioxidant properties and effect on the motility and survival of AGS human gastric carcinoma cells. Molecules 25: 2963.

Swieca, M., Kordowska-Wiater, M., Pytka, M., Gawlik-Dziki, U., Bochnak, J., Zlotek, U. and Baraniak, B., 2018. Lactobacillus plantarum $299 \mathrm{~V}$ improves the microbiological quality of legume sprouts and effectively survives in these carriers during cold storage and in vitro digestion. PLoS ONE 13: e0207793. https:// doi.org/10.1371/journal.pone.0207793

Tallon, R., Arias, S., Bressollier, P. and Urdaci, M.C., 2007. Strainand matrix-dependent adhesion of Lactobacillus plantarum is mediated by proteinaceous bacterial compounds. Journal of Applied Microbiology 102: 442-451. https://doi.org/10.1111/j.13652672.2006.03086.x

Tatad, A.M., Nesin, M., Peoples, J., Cheung, S., Lin, H., Sison, C., Perlman, J. and Cunningham-Rundles, S., 2008. Cytokine expression in response to bacterial antigens in preterm and term infant cord blood monocytes. Neonatology 94: 8-15. https://doi. org/10.1159/000112541

Thompson, H.O., Önning, G., Holmgren, K., Strandler, H.S. and Hultberg, M., 2020. Fermentation of cauliflower and white beans with Lactobacillus plantarum - impact on levels of riboflavin, folate, vitamin B12, and amino acid composition. Plant Foods for Human Nutrition 75: 236-242. https://doi.org/10.1007/s11130-020-00806-2

Twetman, L., Larsen, U., Fiehn, N.E., Stecksen-Blicks, C. and Twetman, S., 2009. Coaggregation between probiotic bacteria and cariesassociated strains: an in vitro study. Acta Odontologica Scandinavica 67: 284-288. https://doi.org/10.1080/00016350902984237

Van Hemert, S., Meijerink, M., Molenaar, D., Bron, P.A., De Vos, P., Kleerebezem, M., Wells, J.M. and Marco, M.L., 2010. Identification of Lactobacillus plantarum genes modulating the cytokine response of human peripheral blood mononuclear cells. BMC Microbiology 10: 293. https://doi.org/10.1186/1471-2180-10-293

Vanderhoof, J.A., Young, R.J., Murray, N. and Kaufman, S.S., 1998. Treatment strategies for small bowel bacterial overgrowth in short bowel syndrome. Journal of Pediatric Gastroenterology and Nutrition 27: 155-160. https://doi.org/10.1097/00005176199808000-00005
Vara, E.J., Brokstad, K.A., Hausken, T. and Lied, G.A., 2018. Altered levels of cytokines in patients with irritable bowel syndrome are not correlated with fatigue. International Journal of General Medicine 11: 285-291.

Von Bultzingslowen, I., Adlerberth, I., Wold, A.E., Dahlen, G. and Jontell, M., 2003. Oral and intestinal microflora in 5-fluorouracil treated rats, translocation to cervical and mesenteric lymph nodes and effects of probiotic bacteria. Oral Microbiology and Immunology 18: 278-284. https://doi.org/10.1034/j.1399-302x.2003.00075.x

Wang, M., Adawi, D., Molin, G., Pettersson, B., Jeppsson, B. and Ahrne, S., 2001. Identification of the translocating bacteria in rats with acute liver injury and their relation to the bacterial flora of the intestinal mucosa. APMIS 109: 551-558. https://doi. org/10.1111/j.1600-0463.2001.apm090710.x

Wang, Q., Sun, Q., Qi, R., Wang, J., Qiu, X., Liu, Z. and Huang, J., 2019. Effects of Lactobacillus plantarum on the intestinal morphology, intestinal barrier function and microbiota composition of suckling piglets. Journal of Animal Physiology and Animal Nutrition 103: 1908-1918. https://doi.org/10.1111/jpn.13198

Waugh, A.W.G., Foshaug, R., Macfarlane, S., Doyle, J.S.G., Churchill, T.A., Sydora, B.C. and Fedorak, R.N., 2009. Effect of Lactobacillus plantarum $299 \mathrm{v}$ treatment in an animal model of irritable bowel syndrome. Microbial Ecology in Health and Disease 21: 33-37. https://doi.org/10.1080/08910600902815553

Weinborn, V., Valenzuela, C., Olivares, M., Arredondo, M., Weill, R. and Pizarro, F., 2017. Prebiotics increase heme iron bioavailability and do not affect non-heme iron bioavailability in humans. Food and Function 8: 1994-1999. https://doi.org/10.1039/c6fo01833e

Williams, J.E., 2003. Portal to the interior: viral pathogenesis and natural compounds that restore mucosal immunity and modulate inflammation. Alternative Medicine Review 8: 395-409.

Woodcock, N.P., McNaught, C.E., Morgan, D.R., Gregg, K.L. and MacFie, J., 2004. An investigation into the effect of a probiotic on gut immune function in surgical patients. Clinical Nutrition 23: 1069-1073. https://doi.org/10.1016/j.clnu.2004.01.010

World Health Organisation (WHO), 2015. The global prevalence of anaemia in 2011. WHO, Geneva, Switzerland.

World Health Organisation (WHO), 2018. The top 10 causes of death. WHO, Geneva, Switzerland. Available at: https://www.who.int/ news-room/fact-sheets/detail/the-top-10-causes-of-death

World Health Organization (WHO), 2020. Micronutrient deficiencies. Iron deficiency anaemia. WHO, Geneva, Switzerland. Available at: https://www.who.int/nutrition/topics/ida/en/

Wullt, M., Hagslatt, M.L. and Odenholt, I., 2003. Lactobacillus plantarum 299v for the treatment of recurrent Clostridium difficileassociated diarrhoea: a double-blind, placebo-controlled trial. Scandinavian Journal of Infectious Diseases 35: 365-367. https:// doi.org/10.1080/00365540310010985

Wullt, M., Johansson Hagslatt, M.L., Odenholt, I. and Berggren, A., 2007. Lactobacillus plantarum 299v enhances the concentrations of fecal short-chain fatty acids in patients with recurrent Clostridium difficile-associated diarrhea. Digestive Diseases and Sciences 52: 2082-2086. https://doi.org/10.1007/s10620-006-9123-3 
Xu, J., Jonsson, T., Plaza, M., Hakansson, A., Antonsson, M., Ahren, I.L., Turner, C., Spegel, P. and Granfeldt, Y., 2018. Probiotic fruit beverages with different polyphenol profiles attenuated early insulin response. Nutrition Journal 17: 34. https://doi.org/10.1186/s12937018-0335-0

Zhang, Y., Li, L., Guo, C., Mu, D., Feng, B., Zuo, X. and Li, Y., 2016. Effects of probiotic type, dose and treatment duration on irritable bowel syndrome diagnosed by Rome III criteria: a meta-analysis. BMC Gastroenterology 16: 62.

Zhang, Y.Z. and Li, Y.Y., 2014. Inflammatory bowel disease: pathogenesis. World Journal of Gastroenterology 20: 91-99. https:// doi.org/10.3748/wjg.v20.i1.91
Zhao, H., Vegi, A. and Wolf-Hall, C., 2017. Screening of lactic acid bacteria for anti-Fusarium activity and optimization of incubation conditions. Journal of Food Protection 80: 1648-1656. https://doi. org/10.4315/0362-028X.JFP-17-100

Zheng, J., Wittouck, S., Salvetti, E., Franz, C., Harris, H.M.B., Mattarelli, P., O’Toole, P.W., Pot, B., Vandamme, P., Walter, J., Watanabe, K., Wuyts, S., Felis, G.E., Ganzle, M.G. and Lebeer, S., 2020. A taxonomic note on the genus Lactobacillus: description of 23 novel genera, emended description of the genus Lactobacillus Beijerinck 1901, and union of Lactobacillaceae and Leuconostocaceae. International Journal of Systematic and Evolutionary Microbiology 70: 2782-2858. https://doi.org/10.1099/ijsem.0.004107 
